Working Paper/Document de travail 2014-28

\title{
Consumer Attitudes and the Epidemiology of Inflation Expectations
}

by Michael Ehrmann, Damjan Pfajfar and Emiliano Santoro 
Bank of Canada Working Paper 2014-28

June 2014

\title{
Consumer Attitudes and the Epidemiology of Inflation Expectations
}

\author{
by \\ Michael Ehrmann, ${ }^{1}$ Damjan Pfajfar ${ }^{2}$ and Emiliano Santoro ${ }^{3}$ \\ IInternational Economic Analysis Department \\ Bank of Canada \\ Ottawa, Ontario, Canada K1A 0G9 \\ mehrmann@bankofcanada.ca \\ 2Department of Economics \\ CentER, EBC, University of Tilburg \\ NL-5000 LE Tilburg, The Netherlands \\ D.Pfajfar@uvt.nl \\ 3ITEMQ, Catholic University of Milan \\ University of Copenhagen \\ 20123 Milan, Italy \\ emiliano.santoro@unicatt.it
}

Bank of Canada working papers are theoretical or empirical works-in-progress on subjects in economics and finance. The views expressed in this paper are those of the authors.

No responsibility for them should be attributed to the Bank of Canada. 


\section{Acknowledgements}

We would like to thank seminar participants at Newcastle University, Lund University, the Bank of Canada and the 2013 CEF meetings in Vancouver. 


\begin{abstract}
This paper studies the formation of consumers' inflation expectations using micro-level data from the Michigan Survey. It shows that beyond the well-established socioeconomic determinants of inflation expectations such as gender, income or education, other characteristics such as the households' financial situation and their purchasing attitudes also matter. Respondents with current or expected financial difficulties, pessimistic attitudes about major purchases, or expectations that income will go down in the future have considerably higher forecast errors, are further away from professional forecasts, and have a stronger upward bias in their expectations than other households. However, their bias shrinks by more than that of the average household in response to increasing media reporting about inflation.
\end{abstract}

JEL classification: C53, D84, E31

Bank classification: Inflation and prices

\title{
Résumé
}

Les auteurs étudient la formation des attentes des consommateurs en matière d'inflation à partir de microdonnées tirées de l’enquête menée par l’Université du Michigan auprès des consommateurs. Ils montrent qu'au-delà des déterminants socio-économiques des attentes d'inflation bien établis comme le sexe, le revenu ou le niveau de scolarité, d'autres caractéristiques telles que la situation financière des ménages et leurs attitudes d'achat sont également importantes. Les répondants qui éprouvent ou anticipent des difficultés financières, qui sont pessimistes à l'égard des gros achats ou qui entrevoient une diminution de leur revenu futur commettent des erreurs de prévision beaucoup plus grandes que les autres ménages; en outre, leurs attentes s'éloignent davantage des prévisions des professionnels et elles comportent un biais à la hausse plus prononcé. Cependant, ce biais se réduit de manière plus marquée que celui du ménage moyen en réponse à une couverture médiatique accrue concernant l’inflation.

Classification JEL : C53, D84, E31

Classification de la Banque : Inflation et prix 


\section{Introduction}

How do consumers form inflation expectations? This question is of critical importance for central banks and macroeconomists, since inflation expectations are known to affect the actual evolution of inflation and of the macroeconomy more generally. Recognizing this importance, central banks have in recent decades devoted considerable effort to anchoring inflation expectations, for instance, by announcing inflation targets. While a substantial body of empirical research has shown how professional forecasters form their inflation expectations (among many others, see Capistran and Timmermann, 2009; Coibion and Gorodnichenko, 2010), much less is known about the formation of inflation expectations by consumers.

A number of factors have been identified that shape the level of inflation expectations. Souleles (2004) shows that consumer expectations are biased and inefficient, with forecast errors being systematically correlated with demographic characteristics. Several socioeconomic characteristics are known to affect inflation expectations - females tend to have higher inflation expectations than men, and inflation expectations tend to decrease with income and education, whereas they are often found to be higher for older consumers (Jonung, 1981; Bryan and Venkatu, 2001; Lombardelli and Saleheen, 2003; Christensen, Els, and Rooij, 2006).

Inflation expectations are also shaped by the inflation that consumers actually experience - first, inflation expectations are shaped much more by the inflation rate of consumption baskets that relate to the respective socio-economic group to which the individual belongs than by the overall inflation indices, at least for low-education and low-income consumers (Pfajfar and Santoro, 2009; Menz and Poppitz, 2013); second, inflation expectations vary positively with the inflation experience that individuals have undergone over their lifetime (Lombardelli and Saleheen, 2003; Malmendier and Nagel, 2013); third, more frequently purchased items have been found to have a higher impact on inflation perceptions and inflation expectations (Ranyard, Missier, Bonini, Duxbury, and Summers, 2008; Georganas, Healy, and Li, 2014).

The evolution of consumers' inflation expectations has also been studied. In his seminal paper, Carroll (2003) has demonstrated that consumers update their expectations only infrequently (roughly once every year), that they respond to media reporting and update toward the expectations of professional forecasters, and that inattention to news generates stickiness in aggregate inflation expectations. Subsequently, a number of contributions have studied the expectations-formation process in more detail. With regard to the updating frequency, Doepke, Dovern, Fritsche, and Slacalek (2008) apply Carroll's framework to European data, and report a somewhat lower updating frequency of around 18 months. Using the Michigan Consumer Survey microdata, Dräger and Lamla (2012) provide evidence that quantitative inflation expectations are adjusted rel- 
atively frequently, whereas the qualitative assessment (whether prices in general will go up, down or stay where they are now) changes less often. Qualitatively, the expectations tend to change mostly if the quantitative adjustment is substantial. Furthermore, they find the updating frequency to vary over the business cycle. Coibion and Gorodnichenko (2012) model the responsiveness of expectations to macroeconomic shocks, and confirm the presence of imperfect information not only for consumers, but much more broadly for professional forecasters, firms, central bankers and financial market participants.

The second aspect of Carroll (2003), the role of media reporting in inflation expectations, has also been taken further by a number of subsequent studies. Inattention by consumers has been found to be important in Mankiw and Reis (2002), Mankiw, Reis, and Wolfers (2004) and Reis (2006). Lamla and Maag (2012) analyze the effect of media reporting on disagreement among forecasters, and find professional forecaster disagreement to be unaffected by media coverage, whereas disagreement among households increases with higher and more diverse media coverage. Pfajfar and Santoro (2009) provide evidence that the effect of news on inflation expectations differs across socio-economic groups, and Easaw, Golinelli, and Malgarini (2013) demonstrate that the rate at which the professional forecasts are embodied in the households' expectations depends on socioeconomic characteristics, such as education. Finally, Pfajfar and Santoro (2013) highlight the importance of differentiating between media reporting on inflation and whether a consumer has actually heard news about prices. Their study replicates Carroll's finding that inflation expectations get updated toward the professional forecasts using aggregate data. However, this is not the case at the individual household level, where most consumers who update actually revise their expectations away from the professional benchmark, but by sufficiently small amounts that they are dominated in the aggregate data by relatively few households who update toward professional forecasts by large amounts. Differences in the magnitude of revisions that take place in response to news have been identified by Armantier, Nelson, Topa, van der Klaauw, and Zafar (2012), who find larger revisions for agents that start off with relatively less precise expectations.

The current paper tries to better understand these findings by studying how the updating processes differ across household groups. The paper expands the previous literature by focusing not only on the well-established socio-economic determinants of inflation expectations such as gender, education and income, but also on other characteristics such as households with difficult current and expected financial situations and with pessimistic consumer attitudes. A small number of related studies have provided some evidence in that direction. Webley and Spears (1986) show that U.K. consumers who think they do less well financially than during the previous year, as well as consumers who expect to be worse off in the subsequent year, have higher inflation expectations. Similarly, del Giovane, Fabiani, and Sabbatini (2009) and Malgarini (2009) find that inflation expectations of Italian consumers are higher for respondents with pessimistic attitudes, and 
for households in financial difficulties. How can this be rationalized? First, if consumers struggle to make ends meet with their available budget, this could be due to a reduction in their income or to an increase in their expenditures - which in turn could be due to several factors, one of them being rising prices for their consumption bundle. Under uncertain information and information-processing constraints, it might well be that such consumers estimate inflation to be higher than others. Second, it has been shown that financially constrained consumers are more attentive to price changes of the goods they purchase than more affluent consumers (Snir and Levy, 2011). Combining this with the well-known notion that agents are more receptive to bad than to good news (see, e.g., Baumeister, Bratslavsky, Finkenauer, and Vohs, 2001) might well imply that financially constrained households arrive at a higher estimate of inflation.

To study the questions at hand, we employ the same data source that has been used in many of the studies following Carroll (2003), namely the Michigan Consumer Survey. This data source has a long history, allowing us to study a time sample from 1980 to 2011. In line with current best practice, we study the microdata from this survey, which enables us to split the respondents according to their characteristics. Our estimates are based on nearly 70,000 observations of inflation expectations by households that are interviewed twice, allowing us to observe how their inflation expectations change over time.

Our first key finding in this paper is that consumer attitudes as well as households' current and expected financial situations have a bearing on inflation expectations. Consumers with pessimistic attitudes about major purchases (such as purchases of durables, houses or vehicles), who find themselves in difficult financial situations, or who expect income to go down in the future have larger forecast errors, are further away from professional forecasts and have a stronger upward bias in their expectations. Broadly, the same holds for low-income households, lower education levels, the elderly and female respondents, as established in the previous literature. ${ }^{1}$

We also confirm the earlier findings that consumers are responsive to news. We employ two news measures, the first based on the survey itself (where respondents can report whether they have recently heard news about prices), and the second following Carroll (2003) based on intensity of news coverage related to inflation in the New York Times and the Washington Post. While both of these measures have been used previously, e.g. in Pfajfar and Santoro (2013), how they differ, and how each of them would have to be interpreted, have not been discussed. In this paper, we clarify that whether respondents have heard news about prices is very tightly linked to gasoline price inflation in the United States. This relationship is in line with earlier evidence that frequently purchased items (such as gasoline) shape the inflation perceptions of consumers, and also likely reflects the fact that gasoline prices are extremely salient due to their prominent postings at gas

\footnotetext{
${ }^{1}$ See e.g. Jonung (1981), Bryan and Venkatu (2001), Lombardelli and Saleheen (2003) and Christensen, Els, and Rooij (2006).
} 
stations.

Interestingly, our two news measures have very different implications for consumer inflation expectations. Having heard news about prices (reflecting predominantly large increases in gasoline prices) increases the bias and worsens forecast accuracy. In contrast, more intense media coverage tends to reduce the bias and improve forecast accuracy. In that regard, our second key finding in this paper is that households with more strongly upward-biased expectations are more responsive to media coverage, and see their bias shrinking by more than the other household groups.

These findings have interesting implications for policy-makers and the media, suggesting that more reporting about inflation improves consumers' inflation expectations, and particularly so for consumers who are in the right tail of the distribution, i.e. have a particularly strong upward bias.

The remainder of the paper is structured as follows. In Section 2, we describe the data used in our empirical analysis and provide some stylized facts. Section 3 provides an overview of the econometric approach that we employ, while Section 4 reports the relevant results. Section 5 concludes.

\section{The Data and Some Descriptive Analysis}

Our household-level data contain information on a wide range of factors that influence consumers' expectations. As such, they allow us to explore the process of expectations updating in greater detail. In this section we describe the key features of the data set and report some preliminary evidence on households' and professional forecasters' inflation expectations, as well as on the newspaper index proposed by Carroll and a direct measure of consumers' receptiveness toward news on prices. Moreover, we report some descriptive statistics about household-level characteristics that are accounted for as determinants of the process of expectations formation.

\subsection{Inflation Expectations}

The Survey of Consumer Attitudes and Behavior is a representative survey conducted by the Survey Research Center at the University of Michigan (Curtin, 2013). The Michigan Survey (henceforth, MS) has been available on a monthly basis since January 1978. The short rotating panel design constitutes its main peculiarity: $40 \%$ of prior respondents are reinterviewed in every round, the remaining $60 \%$ being initial interviews from a random subsample of the mainland U.S. population that has a landline telephone. Since we are interested in how consumers update their inflation expectations, we will restrict our analysis to the second interview, which leaves us with 67,116 observations. From a total of 71,629 reinterviews, we lose $6.3 \%$ of observations due to question attrition (i.e., 4,513 
individuals decided not to provide a year-ahead inflation expectation), which we will control for in our econometric estimates.

Participants are asked two questions about expected changes in prices: first, whether they expect prices to go up, down or stay the same in the next 12 months; second, to provide a quantitative statement about the expected change. ${ }^{2}$

As to professional forecasts, Carroll employs the mean inflation expectation from the Survey of Professional Forecasters (henceforth, SPF). The SPF, currently conducted by the Federal Reserve Bank of Philadelphia, has collected and summarized forecasts from leading private forecasting firms since 1968. The survey questionnaire is distributed once a quarter and asks participants for quarter-by-quarter forecasts, spanning the current and next five quarters. ${ }^{3}$

\section{Insert Figure 1 here}

The analysis will focus on the 1980M1-2011M12 period. ${ }^{4}$ Figure 1 reports mean forecasts of households and professionals against CPI inflation. ${ }^{5}$ Both the MS and the SPF appear to predict inflation reasonably well, although they often fail to match periods of low inflation. For instance, at the very end of the sample, from 2009-11, they are considerably higher than actual inflation turned out to be. This episode has been studied by Coibion and Gorodnichenko (2013), who suggest that, due to high oil price inflation, household inflation expectations were elevated, which in turn help explain the "missing disinflation" in the United States (i.e., the fact that standard Phillips curves would have predicted a disinflation over that period that did not materialize).

\footnotetext{
${ }^{2}$ If a respondent expects prices to stay the same, the interviewer must make sure that the respondent does not actually expect that prices will change at the same rate at which they have changed over the past 12 months. In line with common practice, we discard observations if the respondent expects inflation to be less than $-5 \%$ or more than $+30 \%$. This rule only affects $0.7 \%$ of the observations in the sample under scrutiny. Curtin (1996) also adopts alternative truncation intervals, such as [-10\%,50\%], showing that the key statistical properties of the resulting sample are close to invariant across different cut-off rules.

${ }^{3}$ The SPF was previously carried out as a joint product of the National Bureau of Economic Research and the American Statistical Association on a wide variety of economic variables, including GDP growth, various measures of inflation and the rate of unemployment. For a comprehensive analysis of the SPF forecasts, the interested reader should refer to Croushore (1998). In order to obtain a monthly estimate of the SPF we may consider two options: either forecasters keep their forecast until the next survey round, or their "monthly" forecast includes a partial adjustment to the next quarter forecast. We took both approaches and obtained nearly identical results. In the current version we linearly interpolate between quarters to account for missing monthly observations.

${ }^{4} \mathrm{SPF}$ forecasts of CPI inflation are only available from 1981Q3. Therefore, from 1980Q1 to 1981Q3 we proxy the SPF mean forecast of CPI inflation with the mean forecast of the GDP deflator. The two series are highly correlated.

${ }^{5}$ Inflation expectations sampled at time $t$ are graphed with inflation 12 months later, to be in line with the forecast target.
} 


\subsection{News on Inflation}

A direct implication of Carroll's view is that more media reporting should imply that people are better informed and produce better forecasts. To test this hypothesis, we require reliable indicators of the flow of news on inflation that the public is confronted with. Carroll computes a yearly index of the intensity of news coverage in the New York Times and the Washington Post. In this paper, we use the monthly version of this index that has been constructed in Pfajfar and Santoro (2013). It is based on a search of each of the two newspapers for inflation-related articles, converted into an index by dividing the number of inflation-related articles by the total number of articles. ${ }^{6}$

In addition, our analysis will rely on a measure of consumers' perceptions of new information about prices. This is intended to complement the newspapers index proposed by Carroll. In fact, the accuracy of a proxy based on the intensity of news coverage in national newspapers can be questioned on different grounds. For instance, Blinder and Krueger (2004) suggest that consumers primarily rely on information about inflation from television, followed by local and national newspapers. ${ }^{7}$ It is also plausible to expect that the volume of news about inflation does not necessarily match the flow of information that is assimilated by the public. In this respect, a non-trivial discrepancy could result from the interplay of two mutually reinforcing effects: (i) news from the media does not necessarily reach the public uniformly and (ii) the connection between news and inflation expectations is likely to be affected by consumers' receptiveness to the news and the capacity to process new information. Indeed, Sims (2003) emphasizes the presence of information-processing constraints that could be compatible with such inefficiencies. Finally, it is well known that consumer inflation perceptions are shaped - in line with the availability heuristic (Tversky and Kahneman, 1974) - by frequently purchased items (Ranyard, Missier, Bonini, Duxbury, and Summers, 2008), such that in periods where inflation of such items is high, consumers might be more aware and concerned about inflation, whereas media reporting (which most likely is generally concerned with overall inflation) need not be more intense.

In light of these considerations, it is advisable to complement the analysis with a variable that accounts for consumers' actual perceptions of inflation. Such a variable is directly available from the MS, where respondents are asked whether they have heard of any changes in business conditions during the previous few months. In case of an affirmative response, they have the possibility to give two types of news that they have

\footnotetext{
${ }^{6} \mathrm{~A}$ potential problem connected with this type of search is that the resulting index may include articles that do not primarily cover U.S. inflation. Accordingly, Pfajfar and Santoro (2013) tested the robustness of this methodology by restricting the search to articles that just cover U.S. inflation, and found the results to be robust.

${ }^{7}$ Since Blinder and Krueger (2004), the Internet has become a more important source of news on various economic statistics.
} 
heard about, among them being either higher or lower prices. ${ }^{8}$

Insert Figures 2 and 3 here

Figure 2 reports the fraction of MS respondents who have heard news about prices, together with the newspapers index and CPI inflation. The two series display poor correlation, suggesting that they contain two distinct measures of news. The fraction of MS respondents who have heard news about prices exhibit more volatility than the newspapers index. Especially in the last part of the sample it displays sizable fluctuations that neither actual inflation nor the newspapers index presents. Splitting the series into the share of respondents who have heard news about decreasing and increasing prices, respectively, it is evident that most of the volatility in the overall series arises due to movements in the share of consumers who have heard about rising prices (see Figure 3).

So what is behind this measure of news? As shown in Figure 4, the correlation between the share of respondents reporting that they have heard about price increases and inflation of retail gasoline prices is very high (0.63). ${ }^{9}$ Based on this evidence, we interpret the survey-based news measure as capturing inflation perceptions originating from frequently-purchased items such as gasoline prices. In contrast, the correlation between negative inflation rates in gasoline prices and the share of respondents reporting that they have heard about decreases is much smaller $(0.23)$, which is in line with the prospect theory pioneered by Kahneman and Tversky (1979), since agents tend to manifest higher receptiveness toward "bad" news on prices, as compared with "good" news.

Insert Figure 4 here

\subsection{Household-level Attributes}

The core of our econometric analysis focuses on the connection between consumers' inflation expectations and a number of household-level attributes. These can be grouped in the following categories: the current and expected financial situation, consumer attitudes toward major purchases, and the classifications used in the previous literature, namely gender, income, age and education of the respondent. The attributes are constructed using the survey responses as follows:

\footnotetext{
${ }^{8}$ The MS respondents primarily report about news on unemployment, followed by news on the government (elections) and then prices. It is important to stress that $41 \%$ of the respondents report having heard no news at all and that in $28 \%$ of the cases only one type of news is reported. This is to say that, on average, only $31 \%$ of the respondents are confronted with a potentially binding limit of two options. Therefore, though some underreporting may affect our measure of perceived news about prices, this is not likely to be primarily induced by the specific design of the questionnaire.

${ }^{9}$ For Figure 4, we set any negative gasoline inflation numbers to zero, to reflect the fact that the survey news measure only reflects having heard about price increases.
} 


\section{Financial situation}

- Financial situation worse: Individuals responding "worse" to the following question: Would you say that you are better off or worse off financially than you were a year ago? From this category, we exclude all individuals who name high(er) prices as one reason for being worse off, in order to avoid a possible endogeneity bias.

- Financial expectations worse: Individuals responding "will be worse off" to the following question: Now looking ahead - do you think that a year from now you will be better off financially, or worse off, or just about the same as now?

- Real income expectations worse: Individuals responding "income up less than prices" to the following question: During the next year or two, do you expect that your income will go up more than prices will go up, about the same, or less than prices will go up?

- Nominal income expectations worse: Individuals responding "lower" to the following question: During the next 12 months, do you expect your income to be higher or lower than during the past year?

\section{Purchasing attitudes}

- Time for durable purchases bad: Individuals responding "bad" to the following question: Generally speaking, do you think now is a good or a bad time for people to buy major household items? Again, to avoid possible endogeneity, we exclude all respondents who respond "Prices are too high, prices going up" to the following question: Why do you say so? (Are there any other reasons?)

- Time for house purchases bad: Individuals responding "bad" to the following question: Generally speaking, do you think now is a good time or a bad time to buy a house? Once more, we exclude those who are pessimistic due to high(er) prices.

- Time for vehicle purchases bad: Individuals responding "bad" to the following question: Speaking now of the automobile market - do you think the next 12 months or so will be a good time or a bad time to buy a vehicle, such as a car, pickup, van, or sport utility vehicle? Also here, we exclude individuals who give high or rising prices as a reason for their answer.

\section{Other characteristics, following the previous literature}

- Income bottom 20\%: Individuals in the bottom $20 \%$ of the income distribution (as identified by the MS). 
- Low education: Individuals with education less than 9th grade (i.e., no high school diploma).

- Elderly: Respondents who are at least 65 years old.

- Female: Female respondents.

For each of these categories, we construct a dummy variable that is equal to one in case the attribute applies, and equals zero otherwise.

\section{Insert Figure 5 here}

Figure 5 gives an impression of the time variation in household characteristics, for the example of purchasing attitudes. It reports the share of pessimistic households, and demonstrates that this share varies substantially over time. ${ }^{10}$ It is apparent that at the end of the sample, with the U.S. economy going through the financial crisis and a major recession, many more consumers felt that times were not good for major purchases.

Table 1 provides a number of summary statistics for each consumer group. It indicates how many respondents fall into each category and also provides tests for whether the news reception and the inflation expectations of the various respondent groups are statistically significantly different from those of their peers. The table reports eight different statistics. First, the percentage of households who have heard news about prices $\left(N E W S^{P}\right)$. Second, the updating frequencies of respondents $(U P D T)$, i.e. whether their inflation expectations change from the first to the second interview. Along with this, we also compute the frequency of those who update toward the SPF mean forecast $\left(U P D T^{F}\right)$ and those who move closer to actual inflation $\left(U P D T^{\pi}\right)$. Further, we report the average difference between the MS household-specific forecast and the SPF mean inflation forecast $\left(B I A S^{F}\right)$ and the average difference between the MS household-specific forecast and CPI inflation (at the forecast horizon, $B I A S^{\pi}$ ). Finally, $G A P S Q^{F}$ is the average squared difference between the MS household-specific forecast and the SPF mean inflation forecast, and GAPSQ ${ }^{\pi}$ is the average squared difference between the MS household-specific forecast and CPI inflation (at the forecast horizon), providing us with a measure of their forecast errors.

A number of interesting results emerge. The chosen household groups have higher inflation expectations, higher updating frequencies, worse forecast errors, and tend to be further away from the expectations of professionals than their comparator group. However, there is not much variation in the average frequency at which households update their inflation expectations between the first and the second interview, neither toward

\footnotetext{
${ }^{10}$ Due to the lack of information about the identification of survey respondents taking part in the second interview, it has not been possible to retrieve reliable statistics in the following periods: 1980M3, 1980M12, 1982M11, 1989M11. Therefore, we have opted to treat the corresponding datapoints as missing observations.
} 
the professional forecasters' mean forecast nor actual inflation. While these descriptive statistics are unconditional, i.e. do not correct for possible differences in other characteristics of the various household groups, we will see in the subsequent econometric analysis that even controlling for other characteristics, this overall picture is confirmed.

A question that arises is to what extent the various household categories that we distinguish are correlated, or in other words whether one can assume that they are reasonably independent to warrant a separate analysis. Table 2 reports pairwise Pearson correlations among the attributes we include in the analysis, and shows that even if all the correlations are highly statistically significant, they are not very large from an economic point of view; we therefore proceed on the assumption that the characteristics are sufficiently unrelated to warrant separate analysis and to allow a direct interpretation of their effects.

Insert Tables 1 and 2 here

\section{Econometric Frameworks}

This section explains the main econometric frameworks employed in the analysis. As mentioned earlier, out of an overall sample of 71,629 reinterviewed individuals, 4,513 individuals did not provide their inflation expectations. This may represent a potential source of bias. In order to account for question attrition, we implement the Heckman correction (Heckman, 1979), a procedure that offers a means of correcting for non-randomly selected samples.

\subsection{Bias}

The first question that we will address is whether the inflation expectations of our household groups are more upward biased than those of their peers. For that purpose, we specify the following linear regression model:

$$
\begin{aligned}
B I A S_{i}= & \alpha_{1}+c_{i} \alpha_{2}+N E W S_{i}^{P} \alpha_{3}+N E W S^{N} \alpha_{4}+\mathbf{x}_{i} \alpha_{5} \\
& +c_{i} N E W S_{i}^{P} \alpha_{6}+c_{i} N E W S^{N} \alpha_{7}+u_{i}, \\
B I A S_{i}= & \left\{B I A S_{i}^{F}, B I A S_{i}^{\pi}\right\},
\end{aligned}
$$

where $B I A S_{i}^{F}$ is the difference between the MS household-specific forecast and the SPF mean inflation forecast, and $B I A S_{i}^{\pi}$ is the difference between the MS household-specific forecast and CPI inflation (at the forecast horizon). A comparison with actual, realized inflation will tell us about the overall bias of inflation expectations, whereas the comparison with the $\mathrm{SPF}$ is meant to compare consumer expectations against a forecast that is 
in principle conditional on the same information set, namely the information available at the time of the forecast.

$\alpha_{1}$ is a constant, $c_{i}$ denotes the household classification of interest, $N E W S_{i}^{P}$ is an individual-specific indicator of news perception (which equals one if the interviewee has, in the previous months, heard of recent changes in prices and zero otherwise), and $N E W S^{N}$ indexes the intensity of news coverage at the time of the survey. ${ }^{11} \mathbf{x}_{i}$ is a vector of socioeconomic characteristics (namely gender, age, income, education, race, marital status, location in the United States) ${ }^{12}$ and $u_{i}$ is assumed to be normally distributed. We also interact the household classification variable with each of the news intensity measures. While $\alpha_{2}$ will reveal whether the various household groups differ in their bias, the parameters $\alpha_{6}$ and $\alpha_{7}$ will reveal whether they differ in their response to news.

For these regressions we calculate robust standard errors using the sandwich estimator.

\subsection{Expectations Updating}

We will study two aspects related to the updating of inflation expectations. First, we wish to learn whether our household groups update more often than their peers, given that they are likely to be affected more by changes in inflation. To explore the determinants of expectations updating at the household level, we specify a probit model. The following variable is defined:

$$
z_{i}=\left\{\begin{array}{l}
1 \text { if } z_{i}^{*}>0 \\
0 \text { if } z_{i}^{*} \leq 0
\end{array}, i=1,2, \ldots, N\right.
$$

where $z_{i}^{*}$ is the latent variable that accounts for consumers' expectations updating. Its discrete counterpart, $z_{i}$, takes the value one if the $\mathrm{i}^{\text {th }}$ respondent has changed expectations from the first interview, and zero otherwise. Since individuals are interviewed only twice, the only reference term to determine whether expectations updating has taken place is represented by the response in the second interview. The following latent process is assumed:

$$
\begin{aligned}
z_{i}^{*}= & \alpha_{1}+c_{i} \alpha_{2}+N E W S_{i}^{P} \alpha_{3}+N E W S^{N} \alpha_{4}+\mathbf{x}_{i} \alpha_{5} \\
& +c_{i} N E W S_{i}^{P} \alpha_{6}+c_{i} N E W S^{N} \alpha_{7}+u_{i} .
\end{aligned}
$$

\footnotetext{
${ }^{11}$ In a robustness test, we will also include the last observed CPI inflation rate. We have furthermore considered the possibility that consumers look at alternative inflation measures, such as the average rate of inflation over the six months reinterview period, but did not obtain different results.

${ }^{12}$ Household income is grouped into quintiles and age is measured in integers, while education is split into six groups: "Grade 0-8, no high school diploma," "Grade 9-12, no high school diploma," "Grade 0-12, with high school diploma," "4 yrs. of college, no degree," "3 yrs. of college, with degree" and "4 yrs. of college, with degree." Race is grouped into "White except Hispanic," "African-American except Hispanic," "Hispanic," "American Indian or Alaskan Native" and "Asian or Pacific Islander," while marital status is given as "Married/with a partner," "Divorced," "Widowed," "Never married." Finally, the region of residence is grouped into "West," "North Central," "Northeast," "South."
} 
Standard errors for the marginal effects are calculated with the delta method (Oehlert, 1992).

A second question related to the updating of expectations is whether consumers update toward the SPF or actual inflation, i.e. whether the updated expectations have improved over time. To check for updating toward the SPF, we define a dummy variable that is equal to one if $a b s\left(E_{i, t 2} \pi_{t 2+12}-E_{t 2}^{F} \pi_{t 2+12}\right)<a b s\left(E_{i, t 1} \pi_{t 1+12}-E_{t 1}^{F} \pi_{t 1+12}\right)$, where $E_{t}^{F}$ is the mean expectation operator of the SPF at time $t, t 1$ denotes the time of the first interview, and $t 2$ the time of the second interview. For updating toward actual inflation, the equivalent dummy variable is defined to be equal to one if $a b s\left(E_{i, t 2} \pi_{t 2+12}-\pi_{t 2+12}\right)<$ $a b s\left(E_{i, t 1} \pi_{t 1+12}-\pi_{t 1+12}\right)$. Again, this variable is modelled in a probit framework.

\section{The Determinants of Consumer Inflation Expecta- tions}

Having specified the data and the econometric model, we next discuss the econometric results. First, we analyze whether consumer inflation expectations are biased relative to professional forecasts and relative to actual inflation. Then, we study the updating of expectations.

\subsection{Bias}

Turning to the analysis of the bias, Tables 3 and 4 confirm the previous findings that consumer inflation expectations are biased upwards. The constant reflects the conditional bias of a representative agent with the following characteristics: white (non-Hispanic), married, male, 40 years old, high school diploma, an income in the middle quintile of the distribution and living in the North-Center of the country; the bias is estimated to be statistically significant and positive both when we compare inflation expectations against those of professional forecasters in Table 3 and when we compare against realized inflation in Table 4.

While the inflation expectations of the representative consumer are biased upwards, the bias is substantially larger for the household groups that we study. With the exception of respondents who find their current financial situation to have worsened, all other groups have a larger bias. Relative to professional forecasts, the magnitude ranges from $0.36 \%$ for respondents who are pessimistic about the purchases of durables to $1.2 \%$ for those who expect real income to decline. Similar orders of magnitude are also observed for the bias of the various socio-economic groups that the literature had pointed out previously (e.g., $0.5 \%$ for females, and $1.3 \%$ for the elderly). These results also hold when consumer inflation expectations are compared to actual inflation in Table 4. 
Having heard news about prices, which is heavily influenced by increases in gasoline prices, increases the bias by around 1\%. Interestingly, this effect does not differ across household groups, suggesting that the effect of gasoline price inflation on inflation expectations is universal, and relatively homogeneous across different consumer types. Contrary to having heard news about prices, more media reporting about inflation tends to reduce the bias in inflation expectations. A one-standard-deviation increase in media reporting (i.e., a change in the index by $4 \%$ ), ceteris paribus, leads to a reduction in the bias of around 0.3 to $0.4 \%$ when measured against actual inflation, and of around 0.7 to $0.8 \%$ when measured against the SPF. The effect is estimated to be different across household groups, with a larger reduction in the bias of pessimistic consumers and those in dire financial situations; when calculated relative to actual inflation, the effect often is twice as large as for the average consumer. This result suggests that more news coverage is beneficial in that (i) it reduces the bias in inflation expectations of the average consumer, and (ii) it does so particularly for those consumer groups that had a larger bias to start with. Finally, the inference confirms that it is important to account for question attrition, as we can appreciate from the statistical significance of the coefficient attached to the residuals from the selection regression (rho). This property tends to hold for most of the subsequent econometric analysis.

Insert Tables 3 and 4 here

\subsection{Expectations Updating}

Table 5 reports results for the determinants of the updating frequency, by providing marginal partial effects. A number of results stand out. First, it is apparent that the financial situation and the purchasing attitudes have a bearing on how often households update their inflation expectations - those with difficult current or expected financial situations and those who believe that times are bad for purchasing durables, houses or vehicles are 2 to $4 \%$ more likely to change their inflation expectations between the two survey interviews, an effect that is estimated to be highly statistically significant in all cases. Similar results are also obtained for the standard categorization variables age and gender - only education does not seem to matter.

Consumers who have recently received news about prices are also more likely to update their inflation expectations, and the same holds true for a higher news intensity in the media. Finally, even if there are different updating frequencies across the household groups, there is no evidence that the updating depends on the news intensity in a differential manner.

Insert Table 5 here 
Finally, we look at the prediction of Carroll's (2003) model, namely that more media reporting will lead consumers to update toward a more rational forecast. Table 6 shows results for the probit model that tests whether consumers' inflation expectations in the second interview are closer to those of the SPF than in the first interview; Table 7 compares whether inflation expectations move closer to actual inflation outcomes in the second interview.

Looking at Table 6, it is not apparent whether consumers do indeed update their forecast toward the SPF. For some model specifications, it seems that consumers, on average, update away from professional forecasts when media reporting intensifies, while for most model specifications, no statistically significant effect is found. This is in line with the previous evidence by Pfajfar and Santoro (2013), who found that some consumers update away from professional forecasts, whereas others update toward them - in which case we would not expect to find statistically significant effects. Their paper furthermore shows that most consumers update away from professional forecasts, which is consistent with us finding such an effect in some specifications.

When we study whether consumers' expectations are updated toward actual inflation, i.e. whether actual forecast errors become smaller, results are more interesting (see Table 7). In line with the results in the previous section, we find that consumers who have heard news about rising prices will find their forecast deteriorating, whereas more news reporting in the media tends to make consumers update their forecasts toward actual inflation - even if the magnitude of the effect is small. Interestingly, these effects are not significantly different for the various consumer groups that we distinguish. In combination with the finding that their bias is reduced more strongly in response to media reporting, this suggests that the average consumer adjusts toward actual inflation, but that our consumer groups adjust by larger amounts.

Insert Tables 6 and 7 here

\subsection{Robustness}

We have conducted several robustness checks to investigate the sensitivity of our results to our modelling choices. For brevity, we will only show those that relate to the bias of consumers relative to actual inflation (i.e., those reported in Table 4), but results generally hold also for the other analyses. For the first robustness check, we added lagged actual inflation as an explanatory variable to the regression (see Table 8). As a matter of fact, consumers are responsive to past developments of inflation, with higher inflation rates lowering the bias. The magnitudes by which the bias of our consumer groups is elevated relative to the others remains largely unchanged, as does the effect of perceived news. The coefficients on media reporting are somewhat smaller (reflecting the fact that media reporting is more intense when inflation is high), but the sign remains unchanged: more 
media reporting lowers the bias, and much more so for our respective consumer groups (with the magnitude of the interaction terms being roughly unchanged). ${ }^{13}$

Another robustness test checks for those consumers who are pessimistic about major purchases, or see themselves in a difficult financial situation, but who mention that this is due to increasing prices (whereas, so far, these had been excluded from the household groups). Of course, we would expect these consumers to have a substantially larger bias, and this is indeed the case, as shown in Table 9. The exception is consumers who think that times are bad to purchase a house due to prices - which is intuitive, since these respondents most likely have house prices in mind when answering that question, so they need not have a larger bias with regard to consumer prices. All other results go through with this robustness test - perceived news increases the bias, and media reporting decreases it, and particularly so for the pessimistic households.

\section{Insert Tables 8 to 10 here}

A third robustness test relates to those consumers who have changed their attitudes between interviews (i.e., those who changed their attribute over time, and fell into the category during their second interview, but not during the first interview). Results for the level of the bias, shown in Table 10, are qualitatively unchanged - those who fall into the respective category only during the second interview have a significantly larger upward bias. However, their reaction to media reporting is now estimated to be the same as for all the other consumers, suggesting that media reporting primarily helps reduce the elevated bias of persistently pessimistic consumers.

Finally, our benchmark model contains a variable that indicates whether a respondent has heard news about prices. One might wonder whether the effect would be more prominent had we only included respondents who have heard news about rising prices. As discussed earlier, most of the observations for this variable originate from respondents who have heard about rising prices, whereas very few report to have heard about declining prices. Replacing our variable for perceived news to include only news about rising prices does not alter our results (which are not shown, for brevity).

\section{Conclusions}

How do consumers form inflation expectations? This paper has used the microdata of the Michigan Survey to shed further light on this important question. While it has been well known that a number of socio-economic characteristics such as gender, age, education or income affect inflation expectations, we have shown that the same also

\footnotetext{
${ }^{13}$ In an alternative regression we have also included gasoline price inflation in the set of regressors. However, despite the close connection between hearing news about prices and increases in gasoline prices, the coefficient attached to $N E W S^{P}$ remains statistically significant and preserves its sign.
} 
holds true for consumer attitudes. Having pessimistic attitudes toward the purchase of durables or homes, experiencing or expecting financial difficulties, as well as expectations that household income will go down in the future affects inflation expectations in a substantial fashion. It increases the upward bias that is anyway inherent in consumer inflation expectations and worsens forecast accuracy. The effects are not only found to be statistically significant, they are substantial in magnitude.

Generally, consumer inflation expectations are highly sensitive to perceived news about rising prices, which themselves are tightly connected to the evolution of gasoline prices. Rising gasoline prices are being noticed much more than falling gasoline prices, and they lead consumers to revise their expectations more frequently, but worsen their bias. This is in contrast to media reporting about inflation, which similarly tends to induce a higher updating frequency of consumers. Importantly, however, more intense media reporting lowers the bias, and especially so for pessimistic households and households in dire financial situations.

The findings have important implications for policy-makers. They suggest that more communication about inflation improves consumers' inflation expectations, and particularly so for consumers who are in the right tail of the distribution, i.e. those who have a particularly strong upward bias.

\section{References}

Armantier, O., S. Nelson, G. Topa, W. van der Klaauw, and B. Zafar (2012): "The price is right: updating of inflation expectations in a randomized price information experiment," Staff Reports 543, Federal Reserve Bank of New York.

Baumeister, R., E. Bratslavsky, C. Finkenauer, and K. Vohs (2001): "Bad is stronger than good," Review of General Psychology, 5, 323-370.

Blinder, A. S., And A. B. Krueger (2004): "What Does the Public Know about Economic Policy, and How Does It Know It?," Brookings Papers on Economic Activity, 35(2004-1), 327-397.

Bryan, M. F., and G. Venkatu (2001): "The demographics of inflation opinion surveys," Economic Commentary, (15).

Capistran, C., and A. Timmermann (2009): "Disagreement and Biases in Inflation Expectations," Journal of Money, Credit and Banking, 41(2-3), 365-396.

Carroll, C. D. (2003): "Macroeconomic Expectations Of Households and Professional Forecasters," The Quarterly Journal of Economics, 118(1), 269-298. 
Christensen, C., P. Els, and M. Rooij (2006): "Dutch Households' Perceptions of Economic Growth and Inflation," De Economist, 154(2), 277-294.

Coibion, O., and Y. Gorodnichenko (2010): "Information Rigidity and the Expectations Formation Process: A Simple Framework and New Facts," NBER Working Papers 16537, National Bureau of Economic Research, Inc.

(2012): "What Can Survey Forecasts Tell Us about Information Rigidities?," Journal of Political Economy, 120(1), 116 - 159.

(2013): "Is The Phillips Curve Alive and Well After All? Inflation Expectations and the Missing Disinflation," NBER Working Papers 19598, National Bureau of Economic Research, Inc.

Croushore, D. (1998): "Evaluating inflation forecasts," Working Papers 98-14, Federal Reserve Bank of Philadelphia.

Curtin, R. (1996): "Procedure to estimate price expectations," Mimeo, University of Michigan.

(2013): "Survey of Consumers," Discussion Paper mimeo, Survey Reserach Center, University of Michigan.

del Giovane, P., S. Fabiani, and R. Sabbatini (2009): "What's Behind 'Inflation Perceptions'? A Survey-Based Analysis of Italian Consumers," Giornale degli Economisti, 68(1), 25-52.

Doepke, J., J. Dovern, U. Fritsche, and J. Slacalek (2008): "The Dynamics of European Inflation Expectations," Topics in Macroeconomics, 8(1), 1540-1540.

DrÄGER, L., AND M. J. LAmla (2012): "Updating inflation expectations: Evidence from micro-data," Economics Letters, 117, 807-810.

Easaw, J., R. Golinelli, and M. Malgarini (2013): "What determines households inflation expectations? Theory and evidence from a household survey," European Economic Review, 61(C), 1-13.

Georganas, S., P. J. Healy, and N. Li (2014): "Frequency bias in consumers' perceptions of inflation: An experimental study," European Economic Review, 67(C), $144-158$.

Heckman, J. J. (1979): "Sample Selection Bias as a Specification Error," Econometrica, $47(1), 153-61$. 
Jonung, L. (1981): "Perceived and Expected Rates of Inflation in Sweden," American Economic Review, 71(5), 961-68.

Kahneman, D., And A. Tversky (1979): "Prospect Theory: An Analysis of Decision under Risk," Econometrica, 47(2), 263-91.

Lamla, M. J., and T. MaAg (2012): "The Role of Media for Inflation Forecast Disagreement of Households and Professionals," Journal of Money, Credit and Banking, 44(7), 1325-1350.

Lombardelli, C., And J. Saleheen (2003): "Public expectations of UK inflation," Bank of England Quarterly Bulletin, 43, 281-290.

Malgarini, M. (2009): "Quantitative Inflation Perceptions and Expectations of Italian Consumers," Giornale degli Economisti, 68(1), 53-80.

Malmendier, U., and S. Nagel (2013): "Learning from Inflation Experiences," Mimeo, UC Berkeley and Stanford University.

Mankiw, N. G., And R. Reis (2002): "Sticky Information Versus Sticky Prices: A Proposal To Replace The New Keynesian Phillips Curve," The Quarterly Journal of Economics, 117(4), 1295-1328.

Mankiw, N. G., R. Reis, And J. Wolfers (2004): "Disagreement about Inflation Expectations," NBER Macroeconomics Annual 2003, 18, 209-248.

Menz, J.-O., And P. Poppitz (2013): "Households' disagreement on inflation expectations and socioeconomic media exposure in Germany," Discussion Papers 27/2013, Deutsche Bundesbank, Research Centre.

Oenlert, G. W. (1992): "A Note on the Delta Method," The American Statistician, 46(1), pp. 27-29.

Pfajfar, D., And E. Santoro (2009): "Asymmetries in Inflation Expectations Across Sociodemographic Groups," Mimeo, Tilburg University.

(2013): "News on Inflation and the Epidemiology of Inflation Expectations," Journal of Money, Credit and Banking, 45(6), 1045-1067.

Ranyard, R., F. D. Missier, N. Bonini, D. Duxbury, and B. Summers (2008): "Perceptions and expectations of price changes and inflation: A review and conceptual framework," Journal of Economic Psychology, 29(4), 378-400.

REIS, R. (2006): "Inattentive consumers," Journal of Monetary Economics, 53(8), 17611800 . 
Sims, C. A. (2003): "Implications of rational inattention," Journal of Monetary Economics, 50(3), 665-690.

SniR, A., AND D. Levy (2011): "Shrinking Goods and Sticky Prices: Theory and Evidence," Working Paper Series 17/11, The Rimini Centre for Economic Analysis.

Souleles, N. S. (2004): "Expectations, Heterogeneous Forecast Errors, and Consumption: Micro Evidence from the Michigan Consumer Sentiment Surveys," Journal of Money, Credit and Banking, 36(1), 39-72.

Tversky, A., and D. Kahneman (1974): "Judgment under uncertainty: Heuristics and biases," Science, 185, 1124-1131.

Webley, P., and R. Spears (1986): "Economic preferences and inflationary expectations," Journal of Economic Psychology, 7(3), 359-369. 


\section{Figures and Tables}

Figure 1: CPI Inflation, MS and SPF mean forecasts.

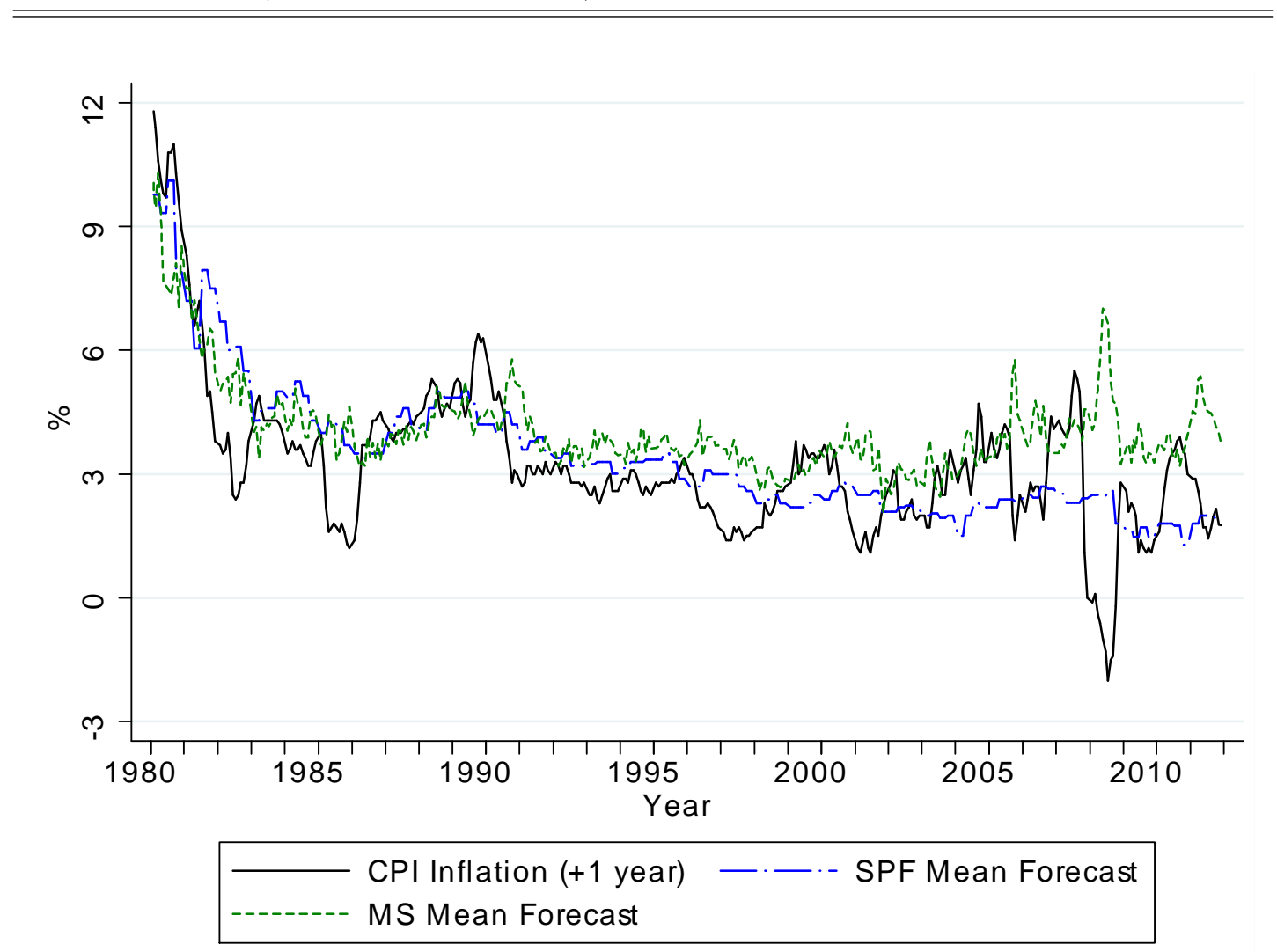

Notes: The chart reports the MS and the SPF mean forecasts for inflation at $t+12$, as well as inflation as realized at $t+12$. Based on monthly data. 


\section{Figure 2: Perceived news and media reporting.}

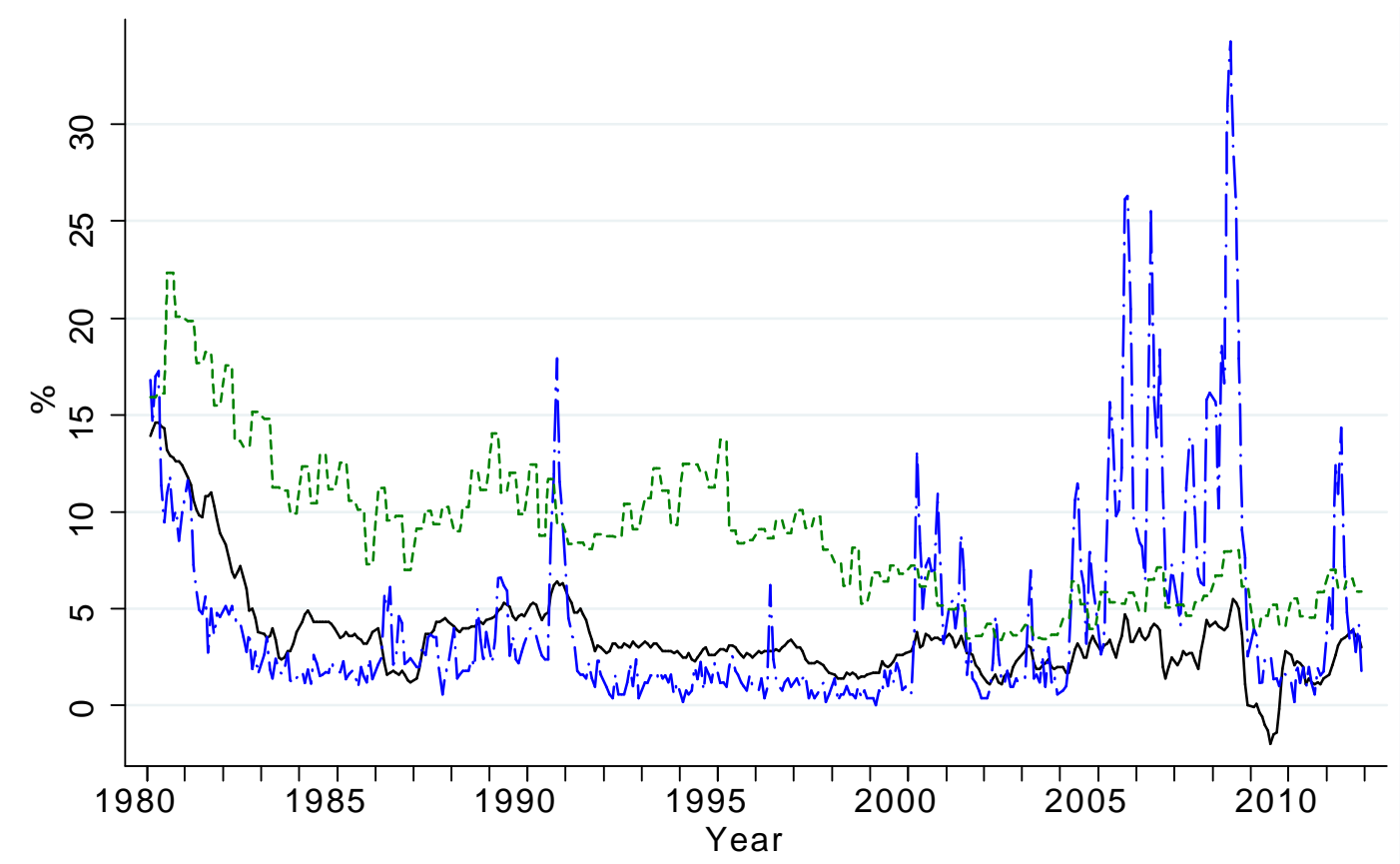

CPI Inflation

Heard about changing prices News Stories

Notes: The chart reports CPI inflation as recorded for a given time period $t$, as well as the share of respondents in the MS in period $t$ answering that they have heard news about prices ("perceived news") and the index about media reporting related to inflation in period $t$ ("news stories"). Based on monthly data. 
Figure 3: Perceived news about increasing / decreasing prices.

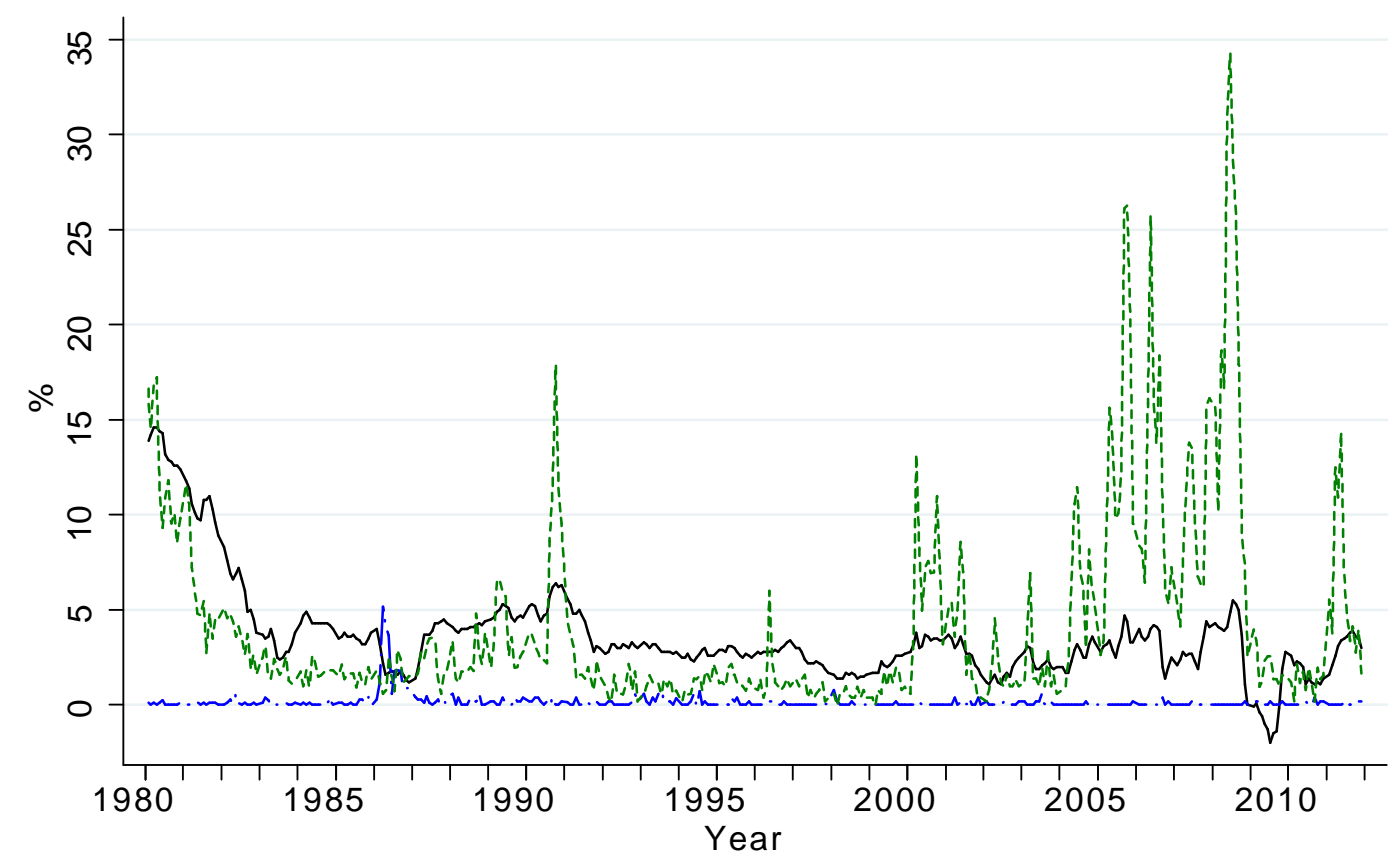

CPI Inflation
-- Heard: increasing prices

Notes: The chart reports CPI inflation as recorded for a given time period $t$, as well as the share of respondents in the MS in period $t$ answering that they have heard about prices increasing / decreasing. Based on monthly data. 
Figure 4: Gasoline inflation and perceived news about increasing prices.

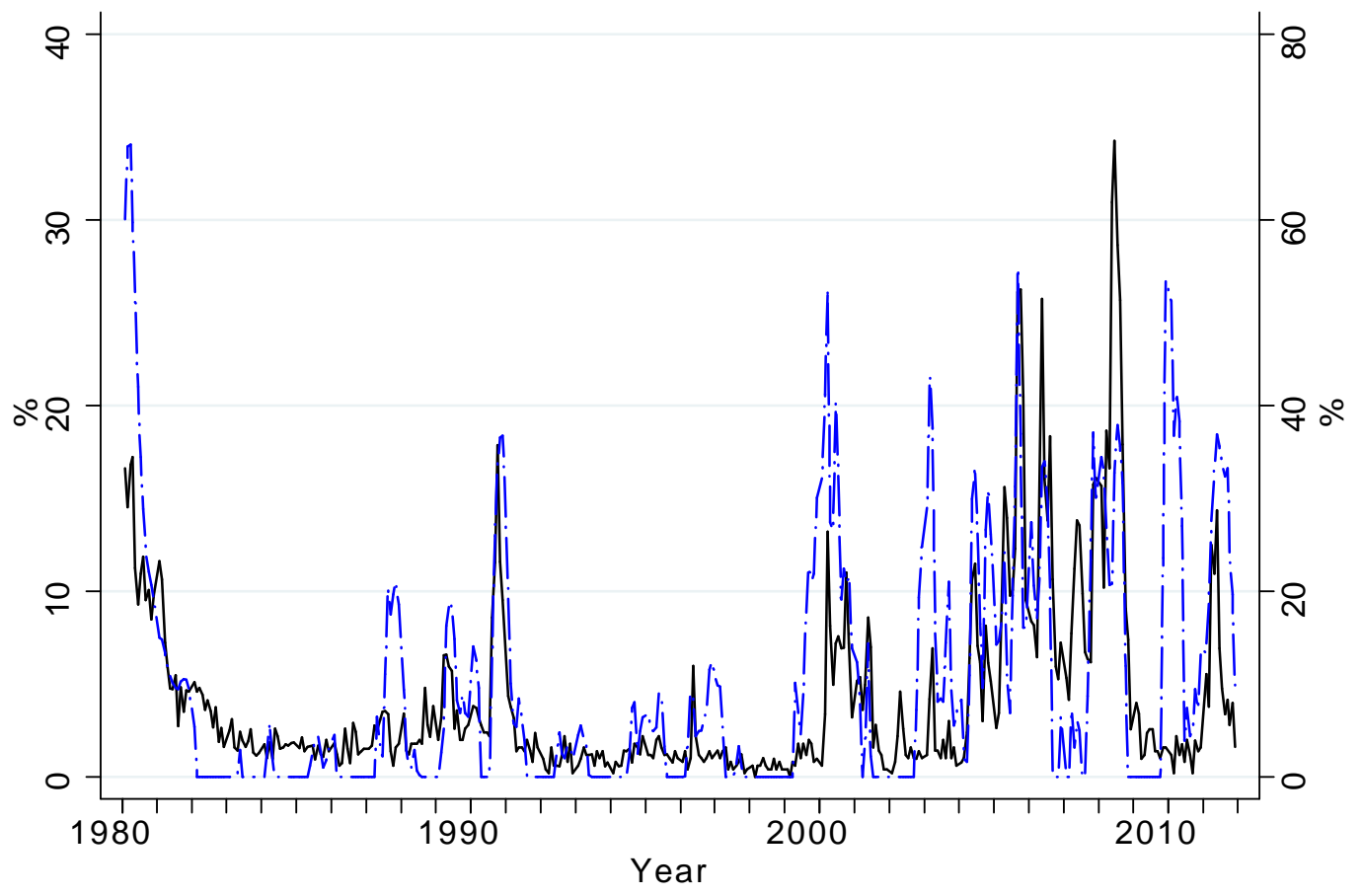

Heard: incr. prices (left axis) - - - Pos. gas. infl. (right axi\$)

Notes: The chart reports the share of respondents in the MS in period $t$ answering that they have heard about prices increasing, as well as retail gasoline price inflation (truncated at zero for negative values). 
Figure 5: Share of pessimistic households.

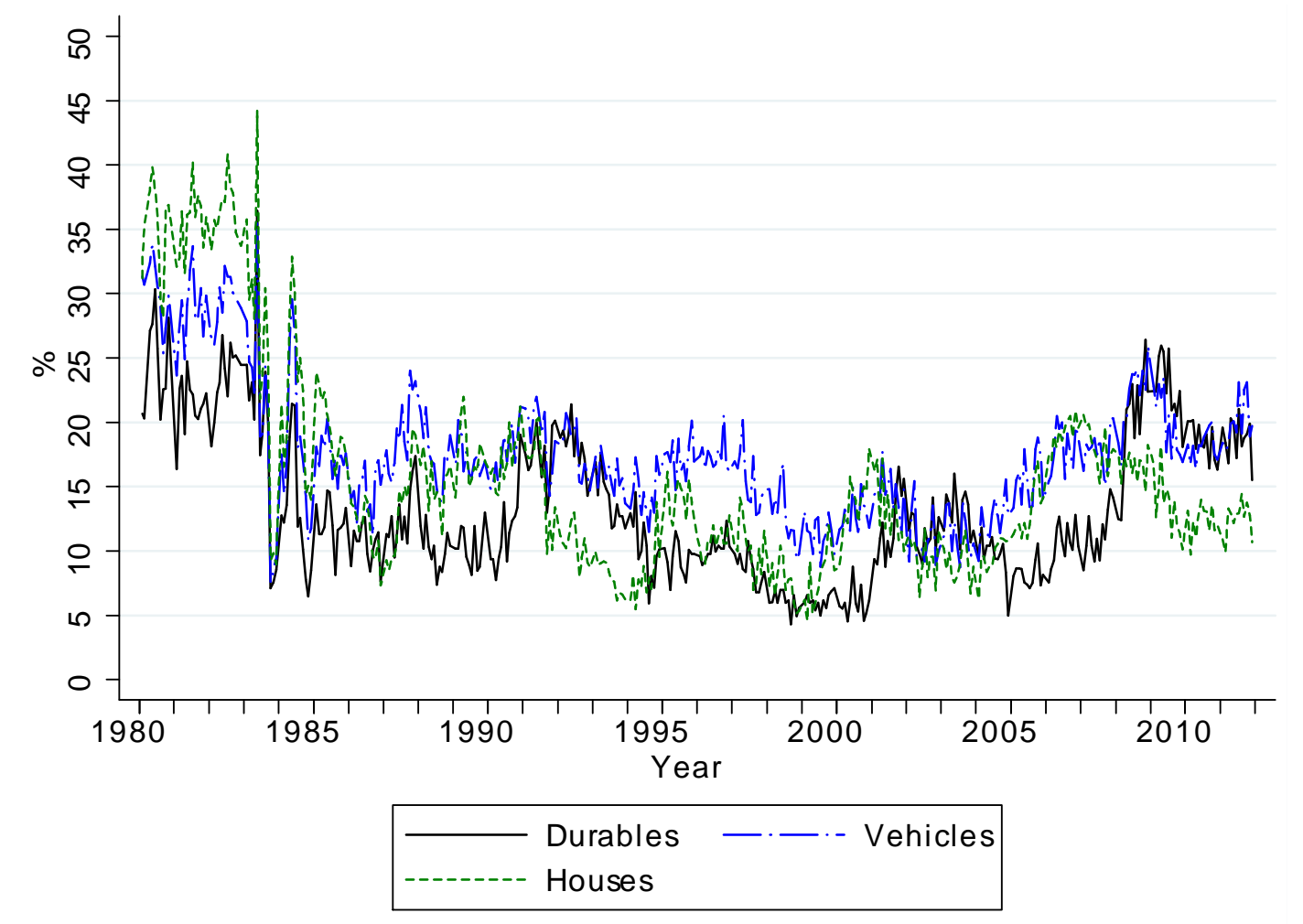

Notes: The chart reports the share of respondents in the MS in period $t$ answering that the time for purchasing durables / vehicles / houses is bad. 


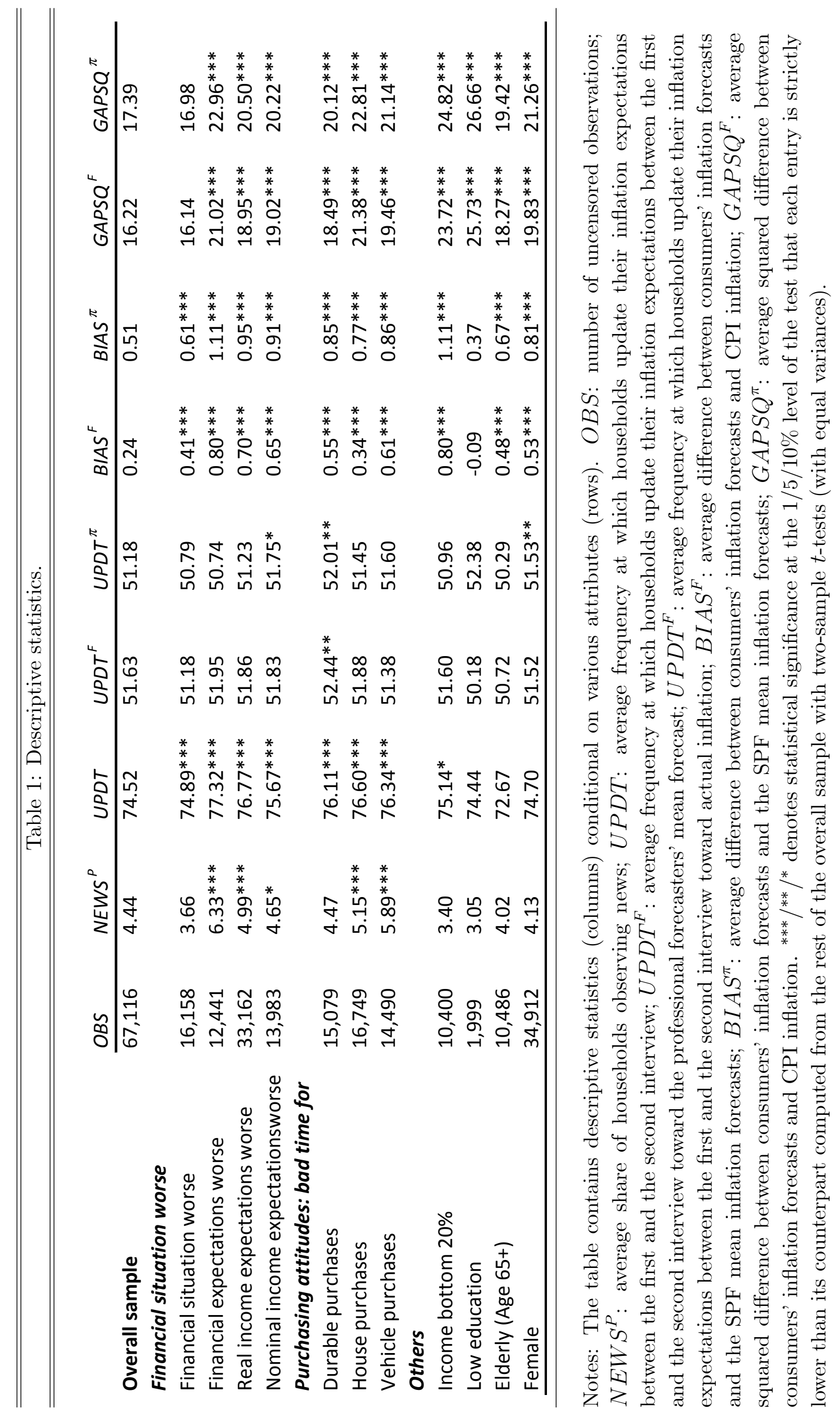




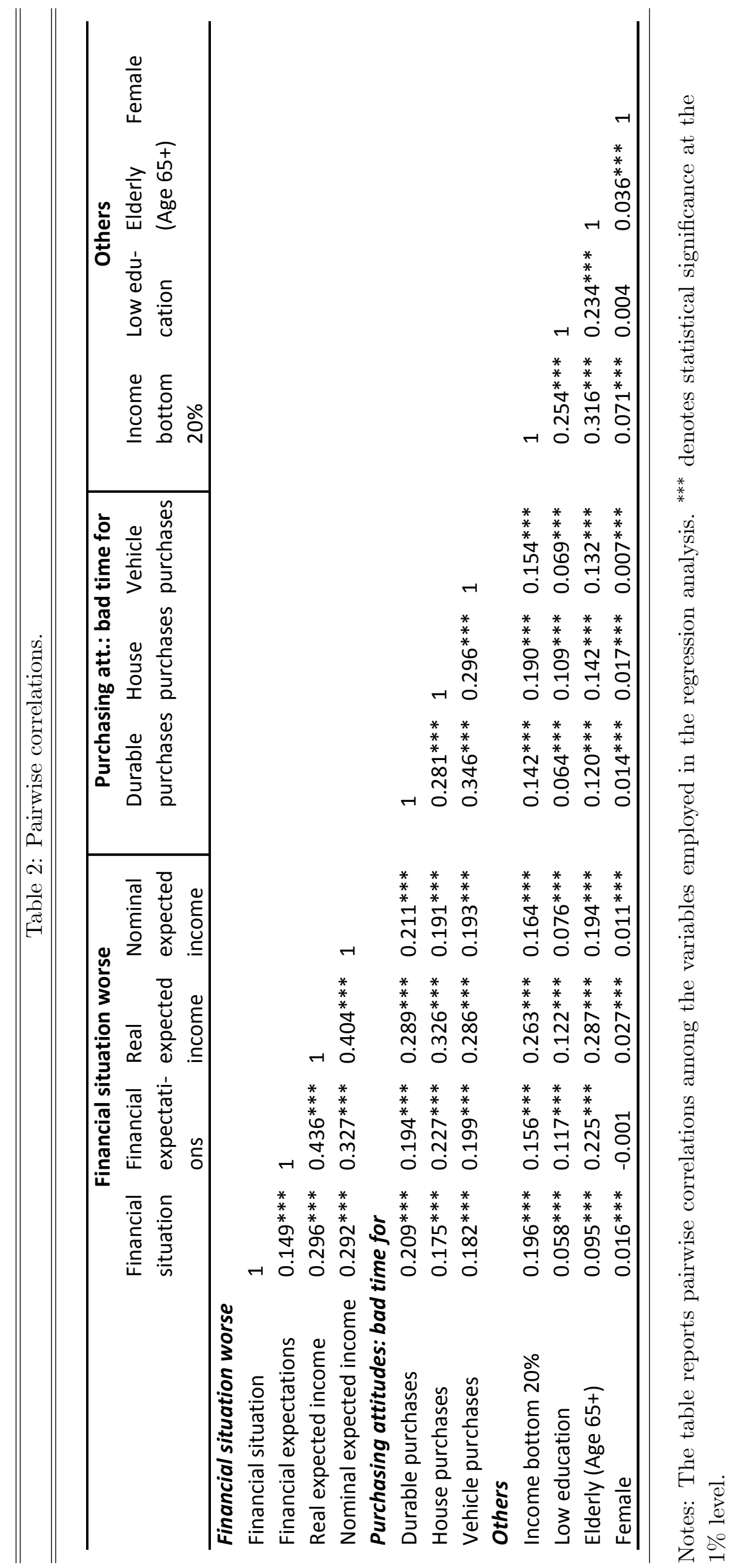




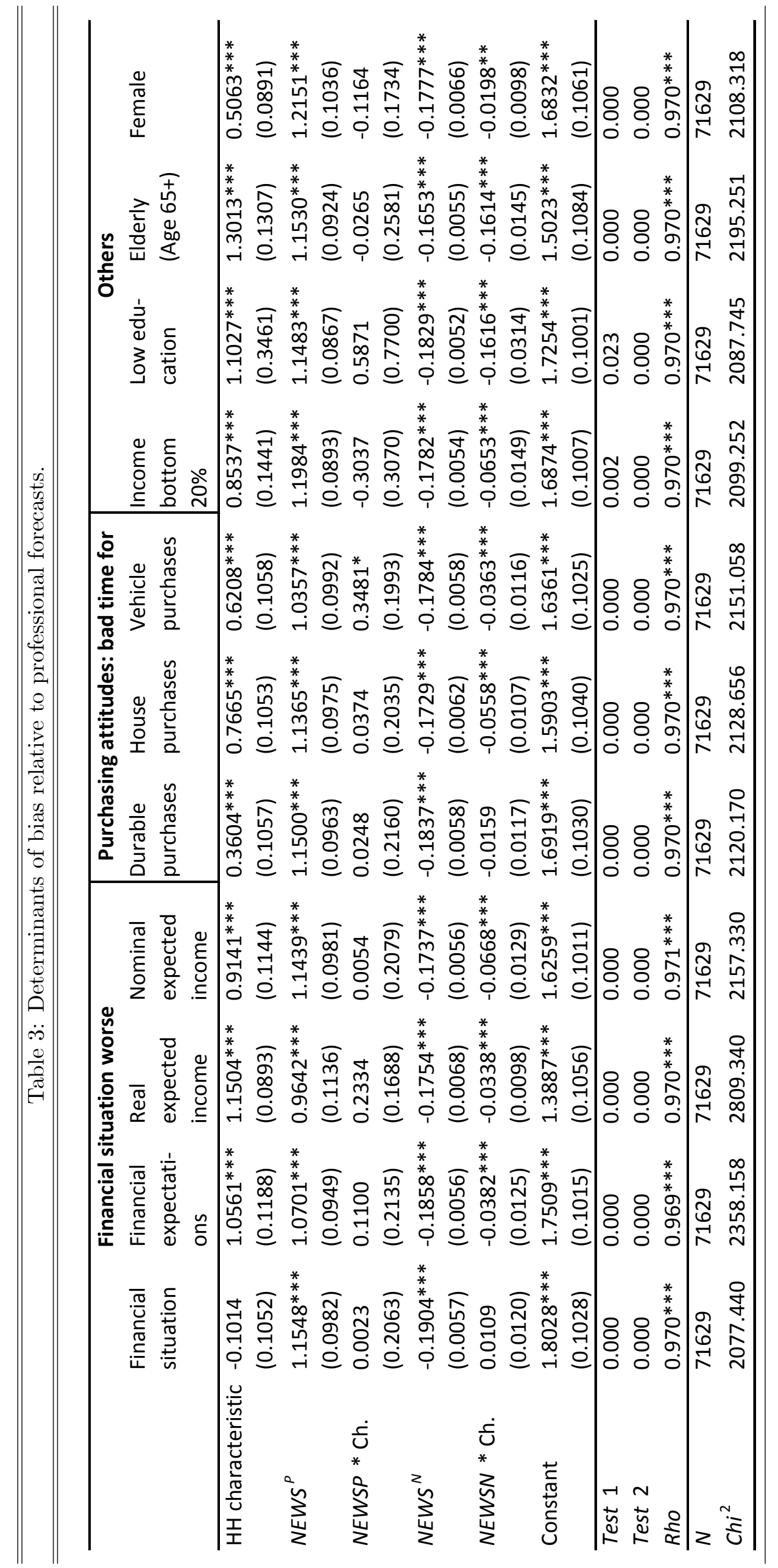

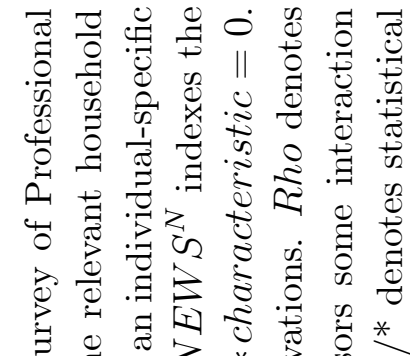

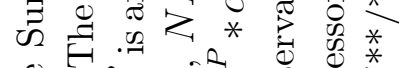
दु के की

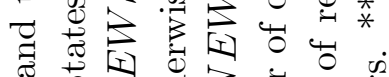

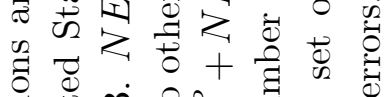
菻苛

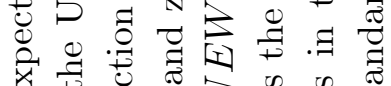

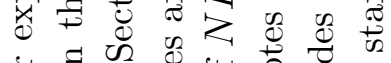

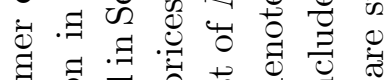
范

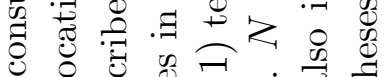
음

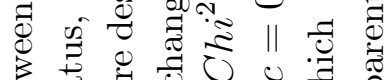

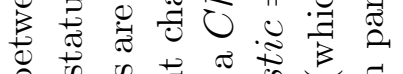
娄

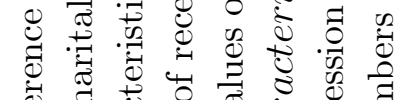

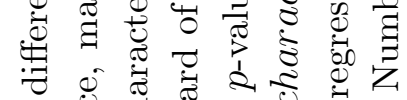

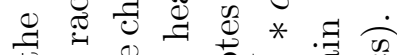

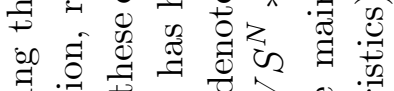
..$\exists$.

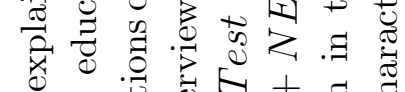
- 0.

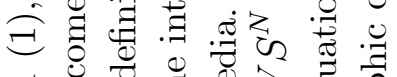
‡: 莺 छ

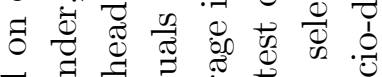
ठ 苟

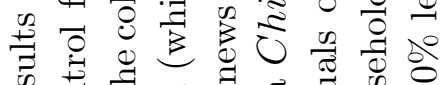

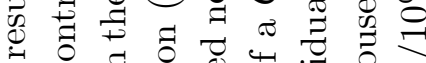

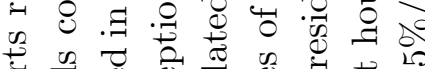

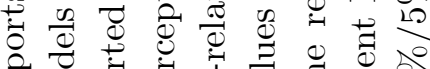
仓ी

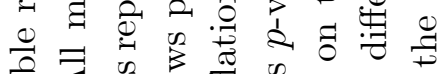

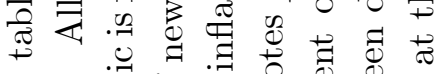

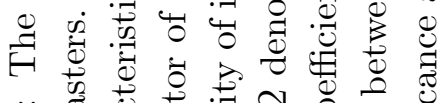

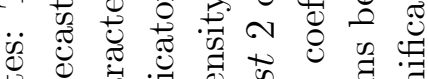

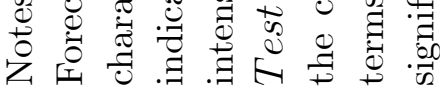




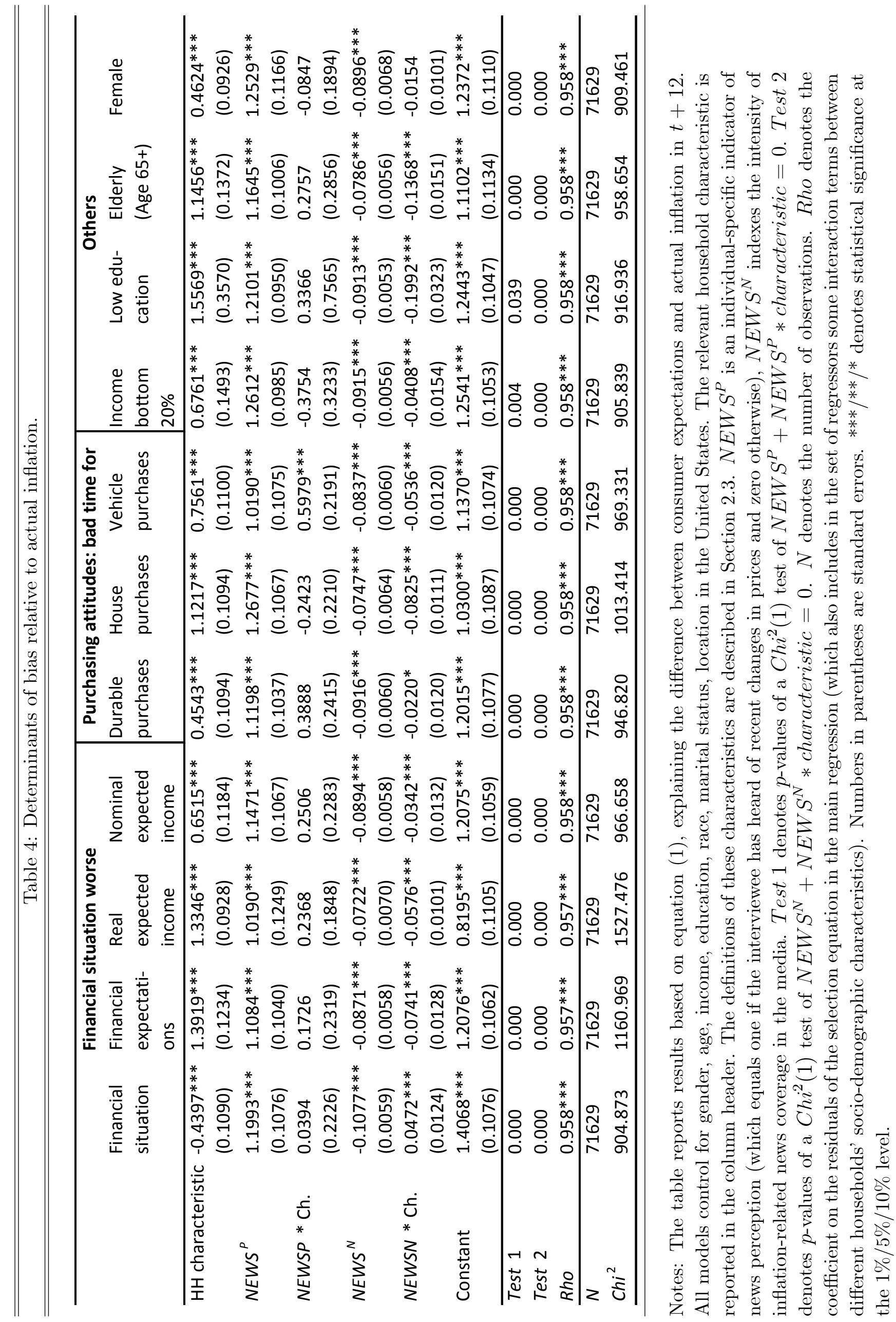




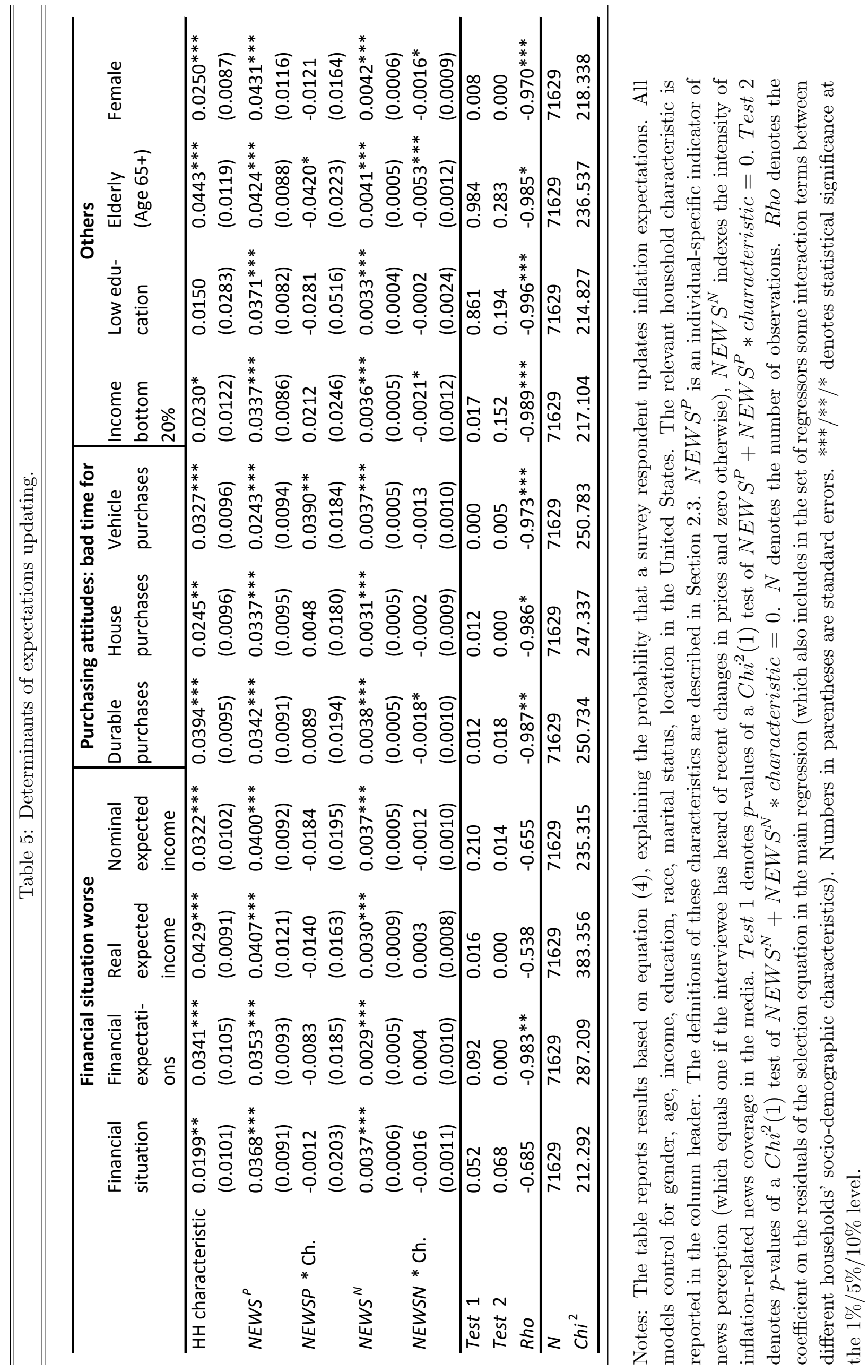




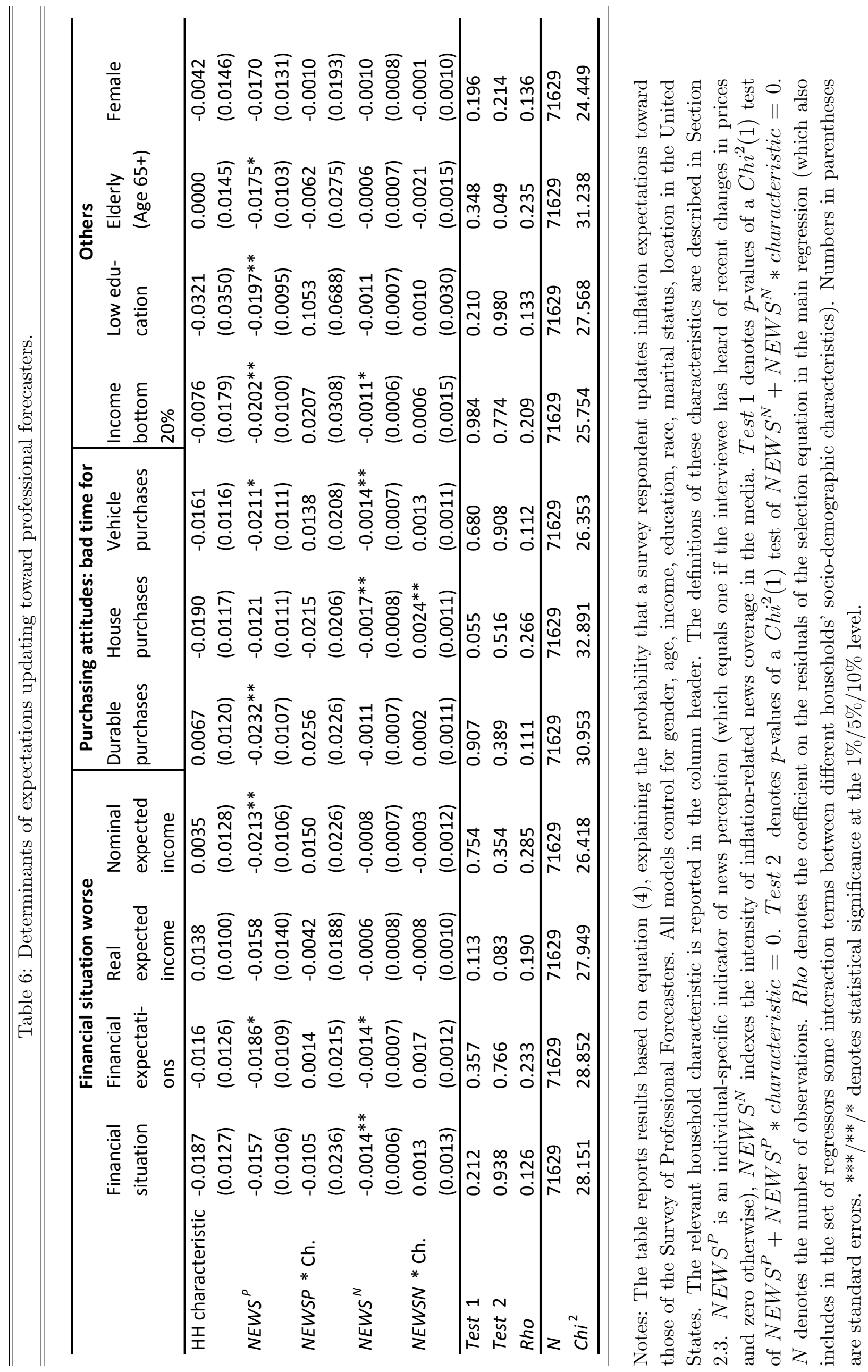




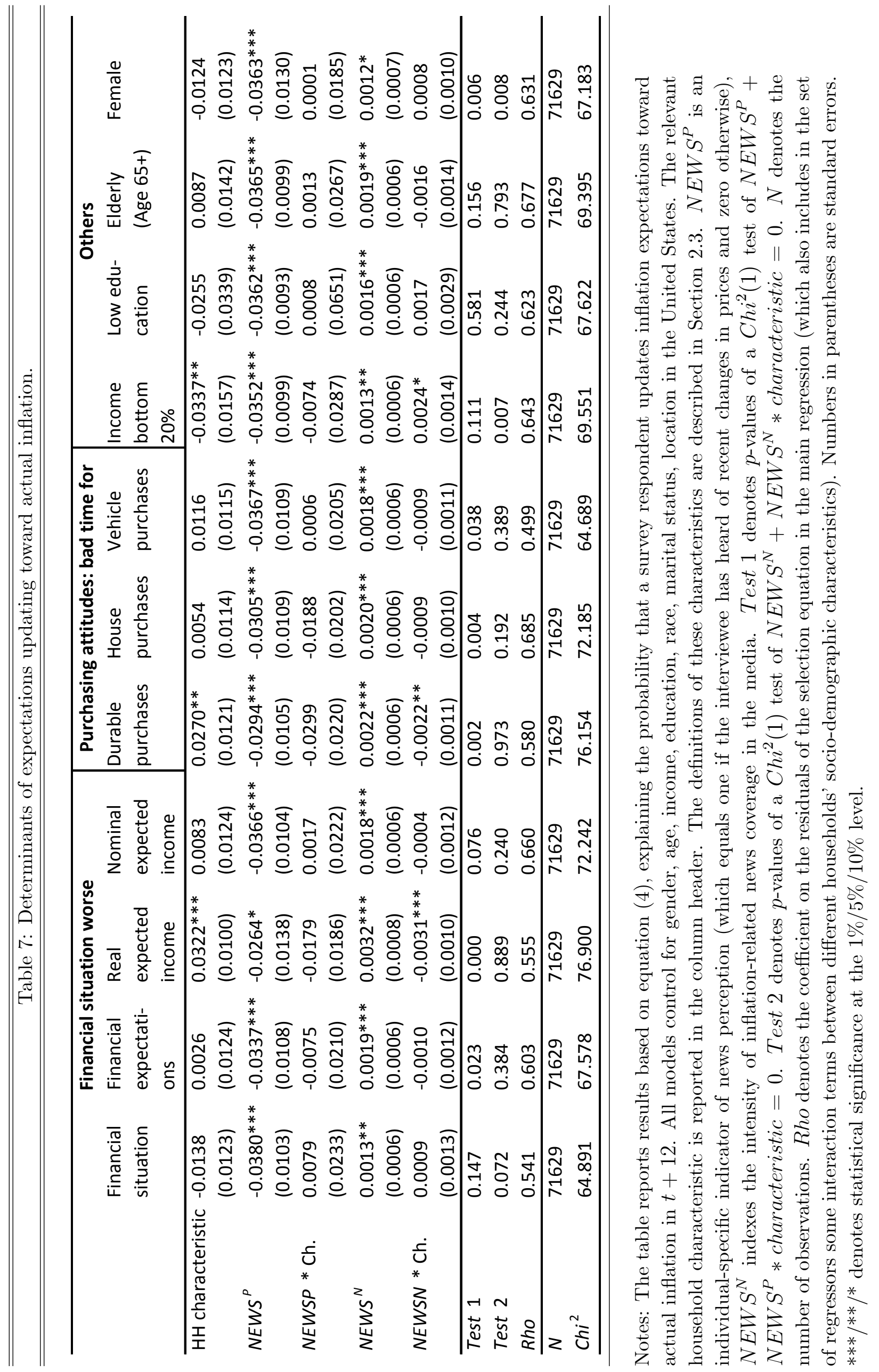




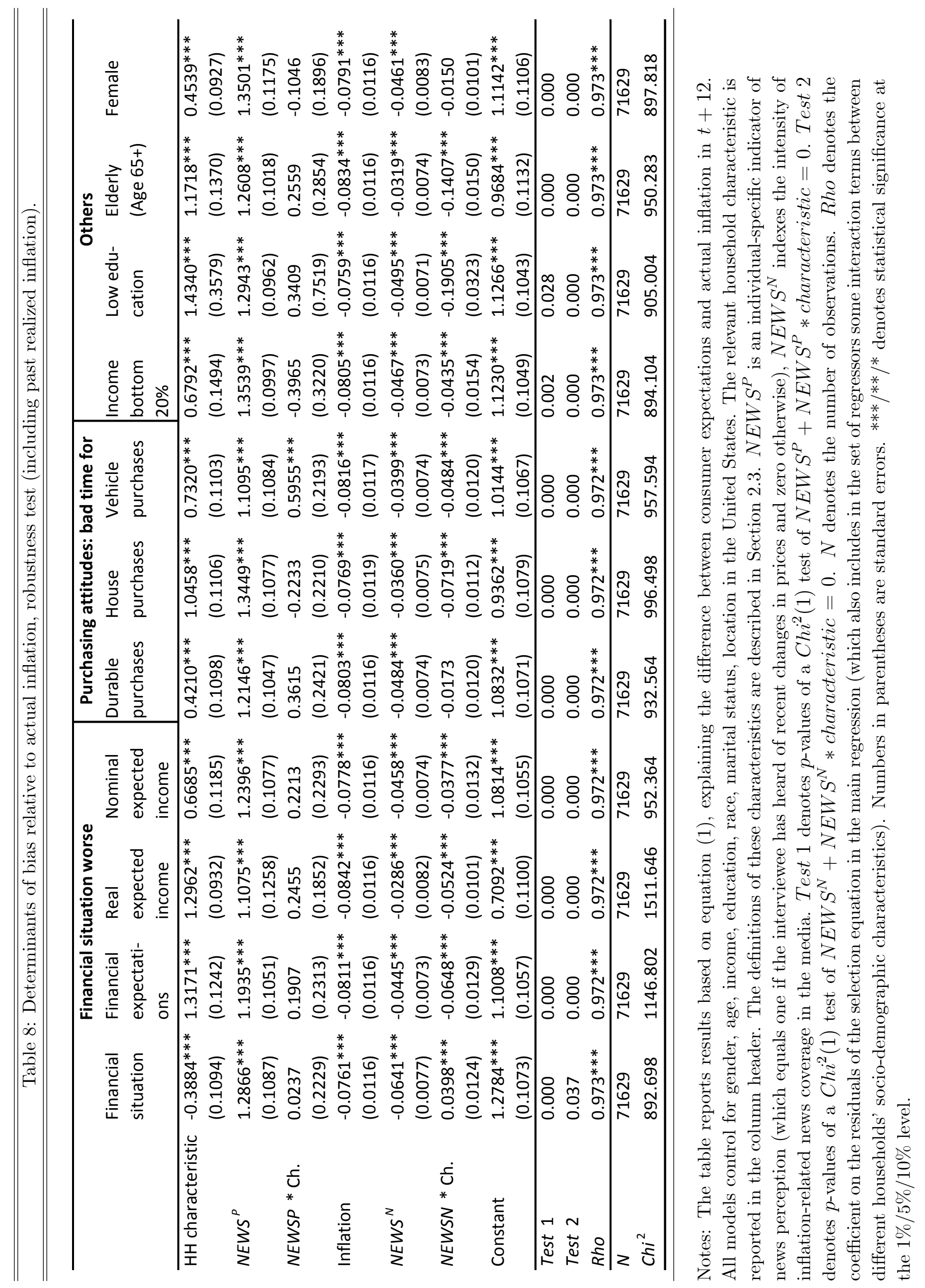




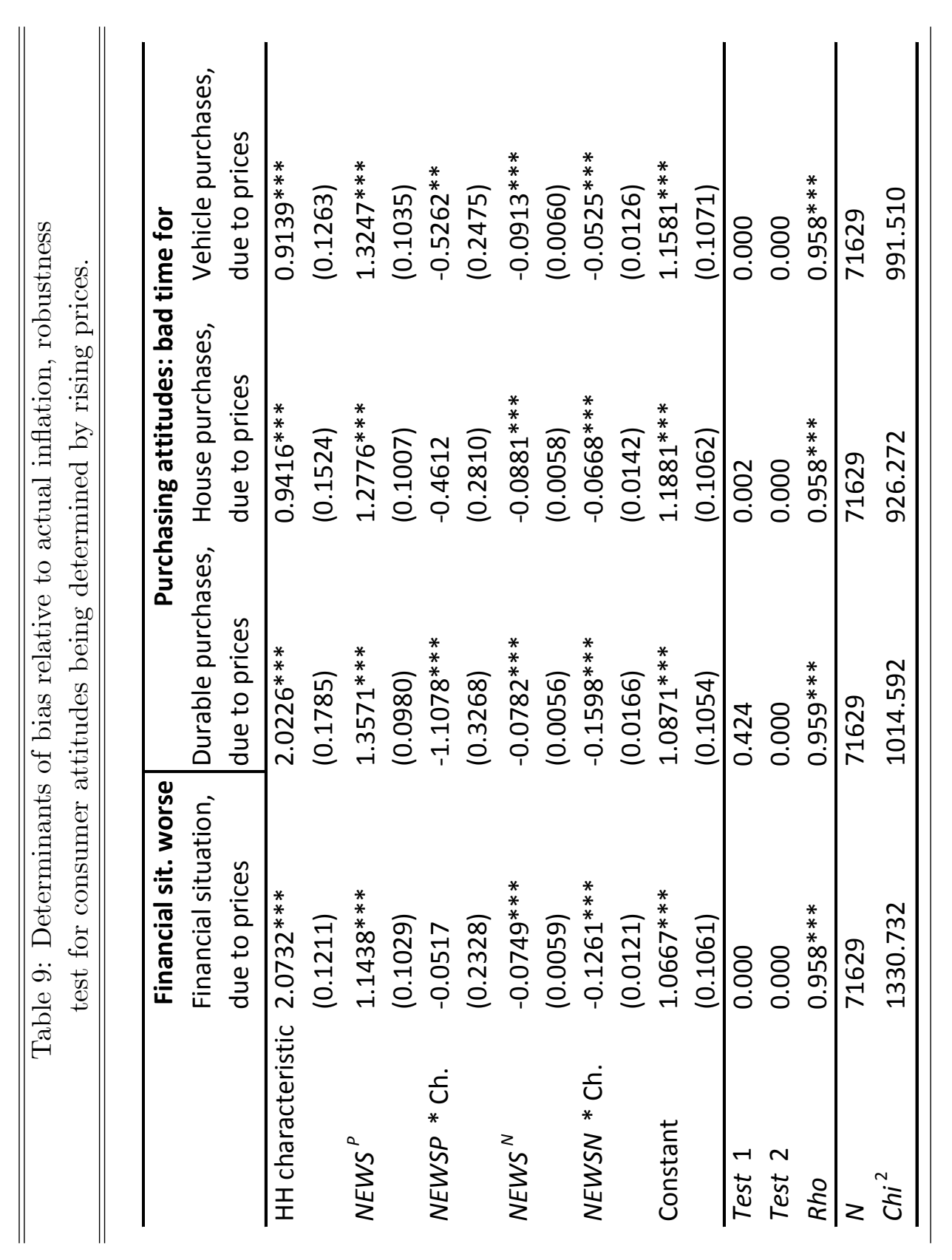

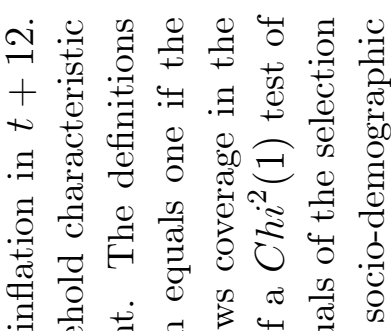

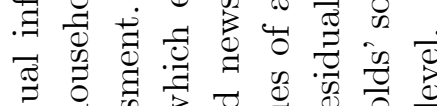

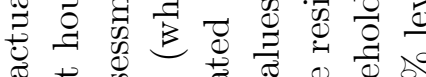
ర สี

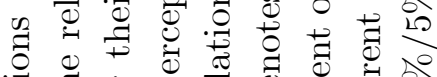

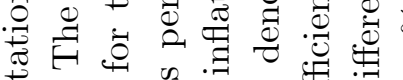

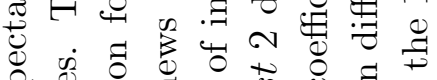

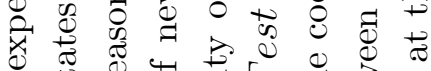

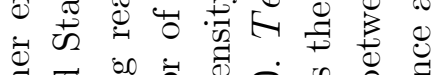

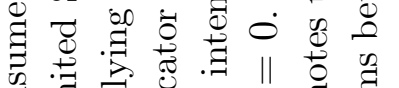

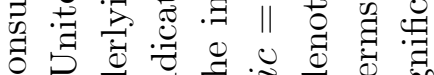

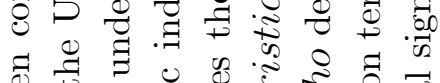

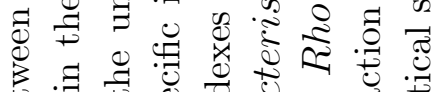

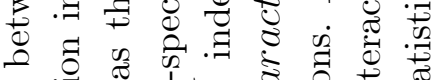
O 过

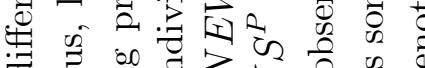

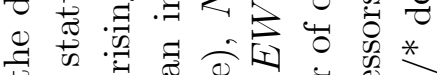

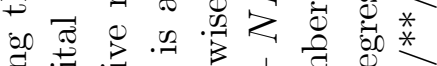

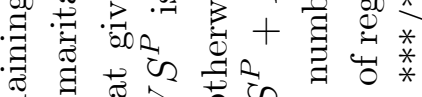

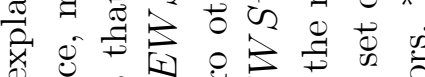

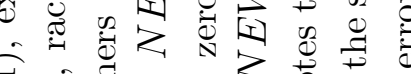
モ

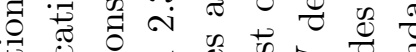
苛

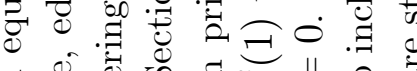

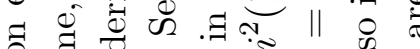

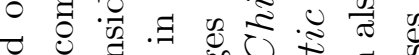
ర్ల ๑ 0 की

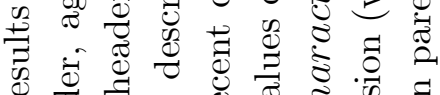

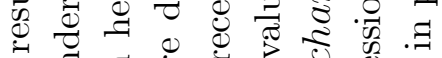

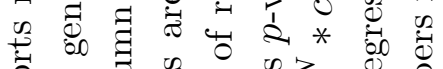
苍

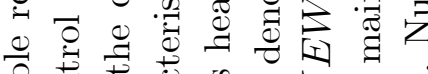

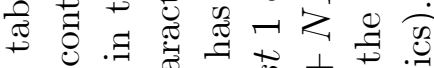
过娄

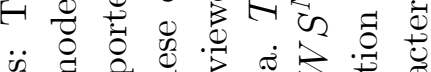

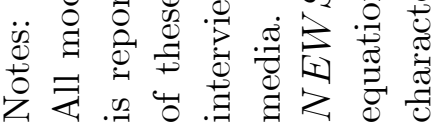




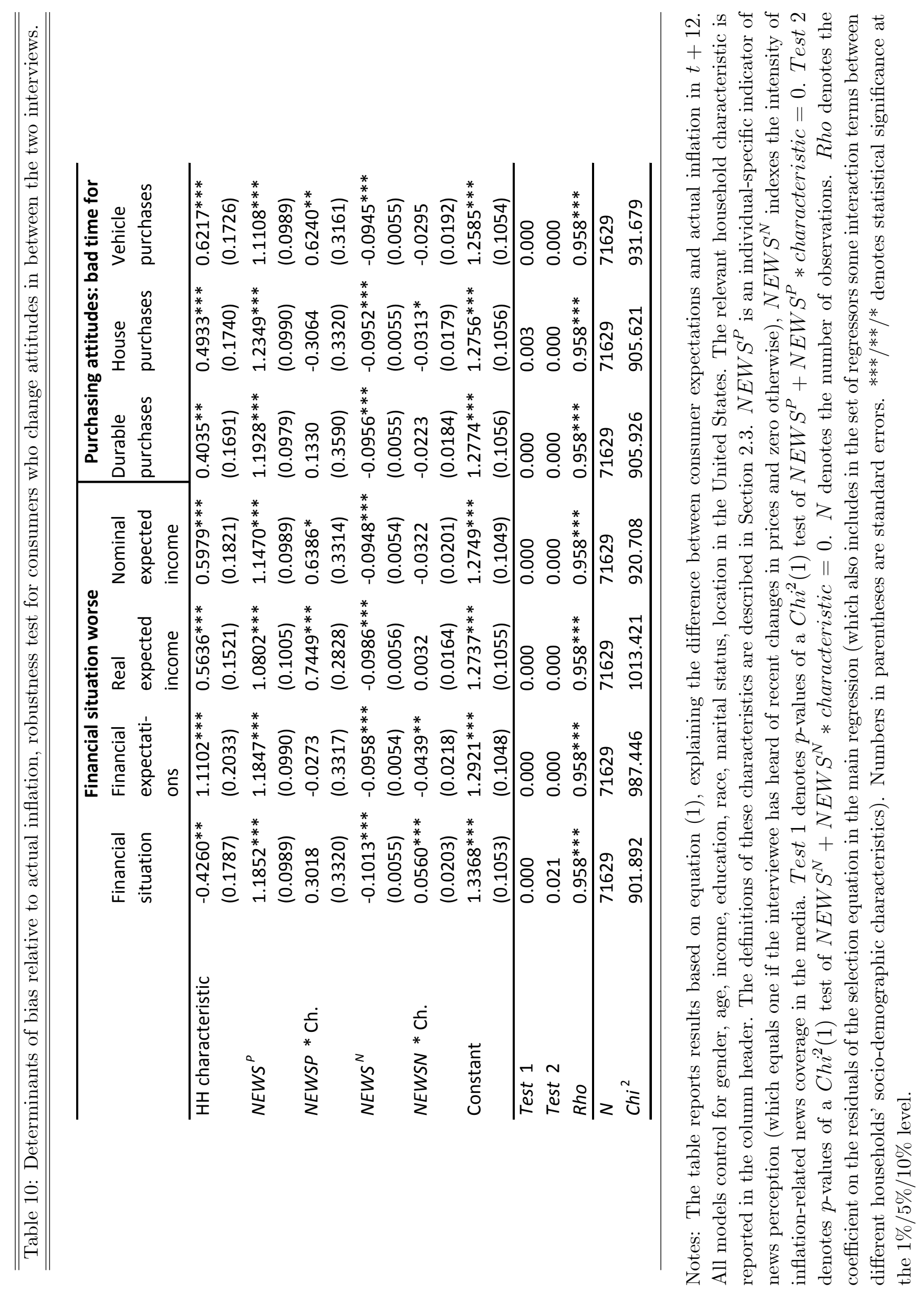

